\title{
The Polar Cap (PC) index combination, PCC: relations to solar wind properties and global magnetic disturbances
}

\author{
Peter Stauning* \\ Danish Meteorological Institute, Lyngbyvej 100, DK-2100 Copenhagen, Denmark
}

Received 24 April 2020 / Accepted 4 December 2020

\begin{abstract}
The non-negative Polar Cap PCC index built from PCN (North) and PCS (South) indices correlates better with the solar wind merging electric field and is more representative for the total energy input from the solar wind to the magnetosphere and for the development of geomagnetic disturbances represented by the Kp index and ring current indices than either of the hemispheric indices. The present work shows that the ring current index, Dst, to a high degree of accuracy can be derived from a source function built from PCC indices. The integration of the PCC-based source function throughout the interval from 1992 to 2018 without attachment to the real Dst indices based on low latitude magnetic observations has generated equivalent Dst values that correlate very well $(R=0.86)$ with the real Dst index values, which are represented with a mean deviation less than $1 \mathrm{nT}$ and an overall RMS deviation less than $13 \mathrm{nT}$. The precise correlation between the real and equivalent Dst values has been used to correct the PCC indices for saturation effects at high intensity disturbance conditions where the Dst index may take values beyond $-100 \mathrm{nT}$. The relations between PCC and the ring current indices, Dst and ASY-H have been used, in addition, to derive the precise timing between polar cap convection processes reflected in the polar cap indices and the formation of the partial and total ring current systems. Building the ring current is considered to represent the energy input from the solar wind, which also powers auroral disturbance processes such as substorms and upper atmosphere heating. With current available PC indices, detailed and accurate SYM-H or Dst index values could be derived up to nearly one hour ahead of actual time by integration of the PCC-based source function from any previous quiet state. Thus, the PCC indices enabling accurate estimates of the energy input from the solar wind are powerful tools for space weather monitoring and for solar-terrestrial research.
\end{abstract}

\section{Introduction}

In the early Space Age, Dungey (1961) formulated the concept of magnetic merging processes taking place at the front of the magnetosphere between the Interplanetary Magnetic Field (IMF), when southward oriented, and the geomagnetic field, followed by the draping of the combined field over the pole and reconnection processes in the tail region, where the solar wind magnetic fields as well as the geomagnetic fields were restored.

The model implies a two-cell convection system, where the high-latitude antisunward ionospheric and magnetospheric plasma drift across the polar cap and the return flow in a sunward motion along auroral latitudes generate the two-cell "forward convection" patterns, now termed DP2. Later, Dungey (1963) extended his model to include cases where IMF is northward (NBZ conditions), which would reverse the convection patterns in the central polar cap and generate sunward transpolar

*Corresponding author: pst@dmi.dk plasma flow (DP3) possibly inside a residual two-cell forward convection system. Although many details have been added later, these solar wind-magnetosphere interaction models still prevail now, 60 years later.

Fairfield (1968) suggested that the maximum amplitude of the magnetic variations observed from a ring of polar cap observatories could be a better indicator of the overall high-latitude magnetic activity than the auroral electrojet indices based on coordinated magnetic observations at auroral latitudes (Davis $\&$ Sugiura, 1966). He also noted that the polar cap magnetic activity sometimes increased before changes in the AE indices were observed.

Kuznetsov \& Troshichev (1977) defined a " $\mathrm{PC}_{\mathrm{L}}$ " index based on the variability of high-latitude magnetic recordings much like present mid-latitude $\mathrm{K}$ (and $\mathrm{Kp}$ ) indices, and not equivalent to the present PC "level index". A "PC(Bz)" index based on a composite of the variance and the level of polar magnetic activity was proposed by Troshichev et al. (1979), who used the Polar Cap magnetic activity as a signature of substorm developments. The "MAGPC" index suggested by 
Troshichev \& Andrezen (1985) was based on the magnitude (in $\mathrm{nT}$ ) of $15 \mathrm{~min}$ samples of the magnetic variation in the direction of the 03:00-15:00 MLT meridian. The MAGPC index was introduced as a measure of the geo-effective interplanetary electric field to be derived from available ground-based magnetic observations in the central polar caps.

A major problem for these initial "PC" indices was their dependence on the daily and seasonal changes in ionospheric conductivity with the varying solar illumination. These variations would generate corresponding variations in the "sensitivity" of the response in the disturbance indices to varying solar wind conditions.

The present version of the Polar Cap (PC) index is based on the formulation by Troshichev et al. (1988). The new idea here is the scaling on a statistical basis of the magnetic variations to the electric field in the solar wind (Kan \& Lee, 1979) in order to make the new PC index independent of local ionospheric properties and their daily and seasonal variations. For the calculation of PC index values they, furthermore, used magnetic variations in an "optimal direction" perpendicular to the DP2 transpolar convection. The PC index concept was further developed by Vennerstrøm (1991) and Troshichev et al. (2006).

The standard Polar Cap (PC) indices, PCN (North) and PCS (South) used also for the PCC index discussed here are derived from polar magnetic variations recorded at Qaanaaq (Thule) in Greenland and Vostok in Antarctica, respectively. The introduction of the non-negative PCC index formed by combining PCN and PCS indices (Stauning, 2007) has resolved two conceptual dilemmas for the interpretation of PC indices assumed representative of the input of energy from the solar wind to the magnetosphere. One is the question of which one of the two hemispherical indices, which at times display considerable differences, would provide the best representation of the incoming solar wind energy. The other dilemma is the problem that a considerable fraction of either index version, as shall be demonstrated, takes negative values. They would then represent outflow of energy to the solar wind leaving the magnetosphere void of magnetic disturbances which could be true in some but far from all cases.

The PC indices have been used in various versions in studies of the relations between polar cap disturbances and further activity parameters such as solar wind electric fields, and magnetospheric storm and substorm indices. In de Campra \& de Artigas (2004), Gao (2012), Gao et al. (2012), Huang (2005), Stepanova et al. (2005), the PCN version developed by Vennerstrøm (1991) were used. Janzhura \& Troshichev (2011) and Troshichev et al. (2011a) used PCN indices in the AARI version while Troshichev et al. (2011b) implemented local summer selections of either PCN or PCS. Troshichev et al. (2012), Troshichev \& Janzhura (2012), and Troshichev \& Sormakov (2019) used both the summer and winter index selection while Troshichev \& Sormakov (2015, 2018) used the average of PCN and PCS indices to represent PC index values in their work. In many calculations and illustrations presented in these publications, the index combination is just named "PC index" and not further specified.

Thus, a prime objective for the present work has been to systematically compare the performances of the individual (unipolar) PC indices and combinations such as non-negative or simple averages or seasonal selections used in correlation studies involving the solar wind merging electric field, $E_{\mathrm{M}}$, the mid-latitude $\mathrm{Kp}$ index, and ring current indices. Such comparisons have not yet been published.

A further prime objective is the clarification of the timing and amplitude relations between polar cap indices (PC) and ring current indices, in particular, the Dst index. Published relations range from simplified rules for the timing and amplitude relations between maximum PC index values and negative peak Dst or SYM-H index values (e.g., Troshichev et al., 2011b; Troshichev \& Sormaov, 2018; ISO/TR/23989, 2020), to neural network-based estimations of Dst values $1 \mathrm{~h}$ ahead from input of past 12 hours PCN and PCS values (Stepanova et al., 2005). The present approach makes it possible to derive precise and detailed ring current intensities by integration of a PCCbased source function from any quiet state $(\mathrm{Dst} \approx 0$ ) up to 45 min past actual time and marks a paradigm shift compared to previous efforts seeking direct relations between PC and SYM-H (or Dst) index values (e.g., relations between PC maxima and Dst or SYM-H minima).

The polar cap indices, PCN and PCS, provide a great potential for Space Weather monitoring and Space Weather-related research (e.g., Stauning et al., 2008; Stauning, 2012). The PCC index construction, as shall be shown, provides more accurate estimates of the solar wind energy that enters the magnetosphere than available from the individual PC indices or further combinations. A particularly important application is the use of strongly enhanced PC index levels (Stauning, 2013c, 2020a) to predict violent substorm events that could threaten important subauroral power grids (Kappenman, 2010).

\section{Calculation of polar cap indices}

The transpolar (noon to midnight) convection of plasma and magnetic fields driven by the interaction of the solar wind with the magnetosphere generates electric (Hall) currents in the upper atmosphere in the opposite direction. These currents, in turn, induce magnetic variations at ground level (Troshichev et al., 1988, 2006; Vennerstrøm, 1991). In order to focus on solar wind effects, the horizontal magnetic variations, $\Delta \mathbf{F}=\mathbf{F}-\mathbf{F}_{\mathrm{RL}}$, of the recorded horizontal magnetic field vector series, $\mathbf{F}$, with respect to an undisturbed reference level, $\mathbf{F}_{\mathrm{RL}}$, are projected to an "optimum direction" in space assumed perpendicular to the DP2 transpolar convection-related sunward currents. The optimum direction is characterized by its angle, $\varphi$, to the dawn-dusk meridian and defines the direction for positive $\Delta F_{\text {PROJ }}$ values. Next, the $\Delta F_{\text {PROJ }}$ scalar values are scaled to generate a PC index equal on the average to the solar wind merging electric field, $E_{\mathrm{M}}$, (also termed $E_{\mathrm{KL}}$ ) formulated by Kan \& Lee (1979):

$$
E_{\mathrm{M}}=V_{\mathrm{SW}} \cdot\left(B_{Y}^{2}+B_{Z}^{2}\right)^{1 / 2} \cdot \sin ^{2}(\theta / 2)
$$

where $V_{\mathrm{SW}}$ is solar wind velocity, $B_{Y}$ and $B_{Z}$ are Geocentric Solar-Magnetosphere (GSM) components of IMF, while $\theta$ is the polar angle of the transverse IMF vector.

The projected polar cap magnetic disturbances are assumed proportional to $E_{\mathrm{M}}$ :

$$
\Delta F_{\text {PROJ }}=\alpha \cdot E_{\mathrm{M}}+\beta .
$$

The PC index is now defined by:

$$
\mathrm{PC}=\left(\Delta F_{\mathrm{PROJ}}-\beta\right) / \alpha\left(\approx E_{\mathrm{M}}\right) .
$$


The optimum angle, $\varphi$, and the propagation delay, $\tau$, between the reference location for the solar wind data and the location for related effects at the polar cap are both estimated from searching the optimum correlation between $E_{\mathrm{M}}$ and $\Delta F_{\mathrm{PROJ}}$ (e.g., Stauning, 2016). The correlation coefficient is usually around 0.75 and the delay from Bow Shock Nose (BSN) to the polar cap is close to $20 \mathrm{~min}$. regardless of the observatory positions in their daily rotation.

The calibration constants, the slope, $\alpha$, and the intercept, $\beta$, are found by linear regression between samples of $\Delta F_{\mathrm{PROJ}}$ and $E_{\mathrm{M}}$ for each moment of the day and year using an extended epoch of past data (Stauning et al., 2006; Troshichev et al., 2006; Stauning, 2016). The regression parameters and the optimum angle values are tabulated throughout the year at 1-min resolution. They are kept invariant over years.

During conditions where the IMF $B_{Z}$ component is negative or small, the forward convection (DP2) patterns prevail and generate positive $\Delta F_{\mathrm{PROJ}}$ values. The slope parameter $(\alpha)$ is positive and the intercept term $(\beta)$ is relatively small. Hence, the PC index values (cf. Eq. (3)) are mostly positive. During positive (northward) IMF $B_{Z}$ (NBZ) conditions, reverse convection patterns (DP3) may emerge and generate negative $\Delta F_{\mathrm{PROJ}}$ values which, in turn, may generate negative $\mathrm{PC}$ index values.

The PCC indices are derived from the mean of non-negative values of the PCN and PCS indices:

$$
\mathrm{PCC}=(\mathrm{PCN} \text { if }>0 \text { or else } 0+\mathrm{PCS} \text { if }>0 \text { or else } 0) / 2 .
$$

Thus, the PCC index values are always non-negative like the merging electric field, $E_{\mathrm{M}}$, used for the calibration of the individual polar cap indices. The rationale behind this formulation builds on a critical assessment of the consequences of negative index values. At negative PC index values in both hemispheres, the global magnetic activity goes low like the PCC index values. A positive PC index in one hemisphere indicates unipolar solar wind energy entry and generation of global magnetic disturbances in agreement with the positive PCC index values even if the PC index for the other hemisphere is dominatingly negative.

It should be noted that the calculations of PCN and PCS index values applied here differ from the IAGA-recommended methods with respect to the handling of reverse convection samples and reference level construction. This issue is discussed in Section 7.

\section{Occurrences of negative PCN and PCS index values}

The occurrences of negative values of the projected magnetic disturbances (reverse convection) and their adverse effects on calculations of index calibration parameters were discussed in Stauning (2013a, 2015). Figure 1 displays an example of negative PCN values.

Note in Figure 1 the strongly negative values of PCN following the abrupt IMF turning northward to make $B_{Z} \approx+4 \mathrm{nT}$ shortly after 15 UT close to local noon (16 UT at Qaanaaq) while the PCS indices are close to zero at this time.

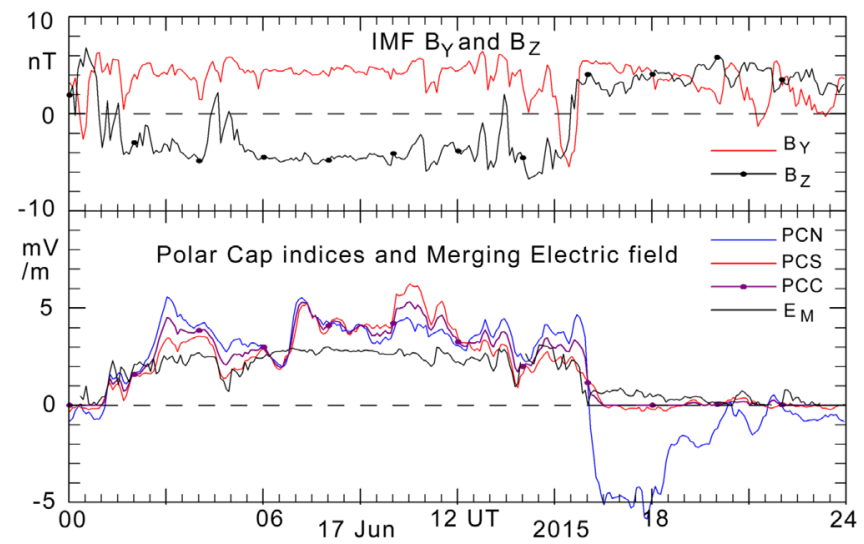

Fig. 1. Upper field: IMF $B_{Y}$ (red line), IMF $B_{Z}$ (black, dots). Lower field: PCN (blue line), PCS (red), PCC (magenta, dots), and $E_{\mathrm{M}}$ values (black) during 17 June 2015.

In this case the mean of PCN and PCS would still be negative and quite large. During the interval of northward $B_{Z}$ (NBZ) conditions with positive IMF $B_{Z}$ values and small $E_{\mathrm{M}}$ values, the PCC index values remain close to zero during the episode of strongly negative PCN and small PCS values. Such events occur most frequently during local midday hours in the summer season.

The daily and seasonal variations in negative PC index values associated with negative values, $\Delta F_{\mathrm{PROJ}}<-50 \mathrm{nT}$, of the projected horizontal disturbance vector (cf. Eq. (3)) associated with reverse convection conditions, are illustrated in Figures $2 \mathrm{a}$ and $2 \mathrm{~b}$. The $-50 \mathrm{nT} \Delta F_{\mathrm{PROJ}}$ level corresponds to a PC index value of around $-1 \mathrm{mV} / \mathrm{m}$.

The differences between the two polar cap observatories are evident in Figures 2a and 2b. Figure 2a shows that the reverse convection conditions mainly occur at around 16 UT for Qaanaaq, which is close to local noon whether in geomagnetic or geographic time. For Vostok, geomagnetic and geographic noon are more separated, which generates the double-peak structure in the daily variation. For the yearly variation both observatories display clear local summer maxima. The total reverse convection intensities are significantly different for the two observatories. The reverse convection intensities summed over the years 1997-2009 amounts to $-2.2 \times 10^{5} \mathrm{nT}$ hours for Qaanaaq and $-0.74 \times 10^{5} \mathrm{nT}$ hours for Vostok as noted in the diagrams of Figure 2 (Stauning, 2015). This difference has a significant impact on the symmetry of index scaling parameters and index values for the two unipolar PC indices.

With forward convection cases with positive values, $\Delta F_{\mathrm{PROJ}}>50 \mathrm{nT}$, of the projected horizontal disturbance vector during the same span of years (1997-2009), the total convection intensities amount to around $2.5 \times 10^{6} \mathrm{nT}$ hours for both observatories (Stauning, 2015). Thus, on the average, reverse convection intensities are around $10 \%$ of the forward convection integrated intensities for Qaanaaq and only 3\% for Vostok. For both observatories, the relative amounts of reverse convection cases are significantly higher at midday in the summer season compared to different local hours and seasons. For Qaanaaq the peak reverse convection intensities (cf. Figs. 2a and 2b) are around $4 \times 10^{3} \mathrm{nT}$ hours/h during summer daytime conditions while the forward convection at 
(a)

(b)
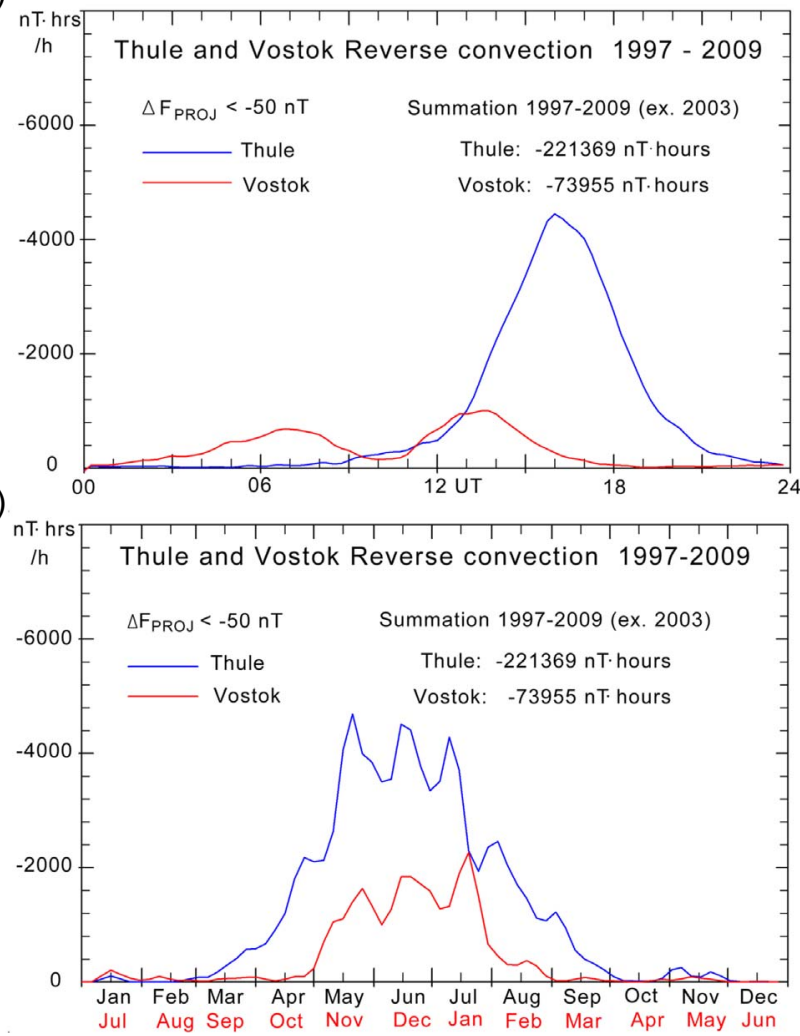

Fig. 2. (a) Average daily and (b) average seasonal variations in reverse convection intensities for Qaanaaq (THL) (blue line) and Vostok (red) defined by the hourly product of amplitude (in nT) and duration (hours).

summer daytime is around $1.5 \times 10^{4} \mathrm{nT}$ hours/h. Thus the peak reverse convection intensities are around $25 \%$ of the forward convection intensities for Qaanaaq, while for Vostok the reverse convection intensities are only around $6 \%$ of the forward convection intensities during local summer daytime conditions.

\section{Relations of PCN, PCS and PCC to the merging electric field, $E_{M}$}

The relations of the polar cap indices, PCN, PCS and PCC to the merging electric field, $E_{\mathrm{M}}$ (Eq. (1)), in the impinging solar wind have been investigated for the span of years from 1992 to 2018. The magnetic data supplied from Intermagnet (https://intermagnet.org) for Qaanaaq (THL) and Vostok have been supplemented since 2009 by data from Dome-C observatory in Antarctica (Chambodut et al., 2009; Di Mauro et al., 2014). All index values have been derived by using the DMI index calculation methods and coefficients (Stauning, 2016). Figures $3 \mathrm{a}$ and $3 \mathrm{~b}$ display hourly values of the $X$ and $Y$ components of the magnetic recordings from Qaanaaq operated by the Danish Space Research Institute (DTU Space) and from Vostok operated by the Arctic and Antarctic Research Institute (AARI) in St. Petersburg. Special care for index calculations was given to data from Vostok since there is, apparently, a base level (a)
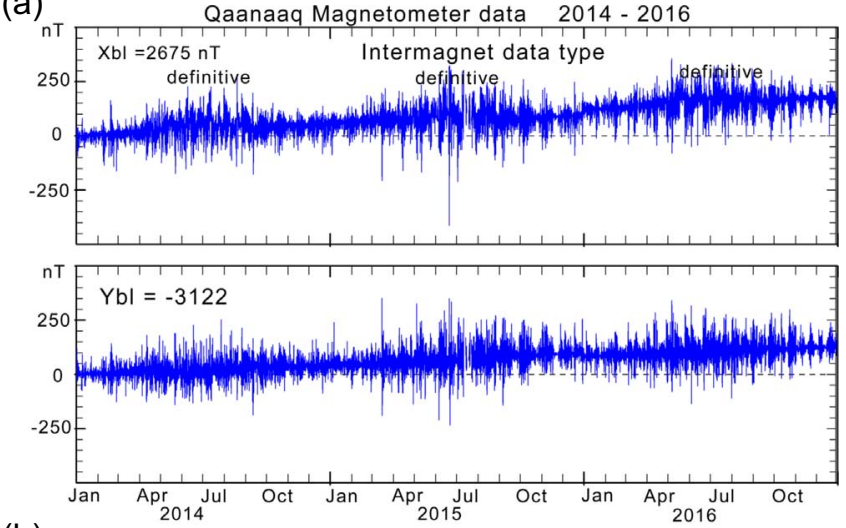

(b)

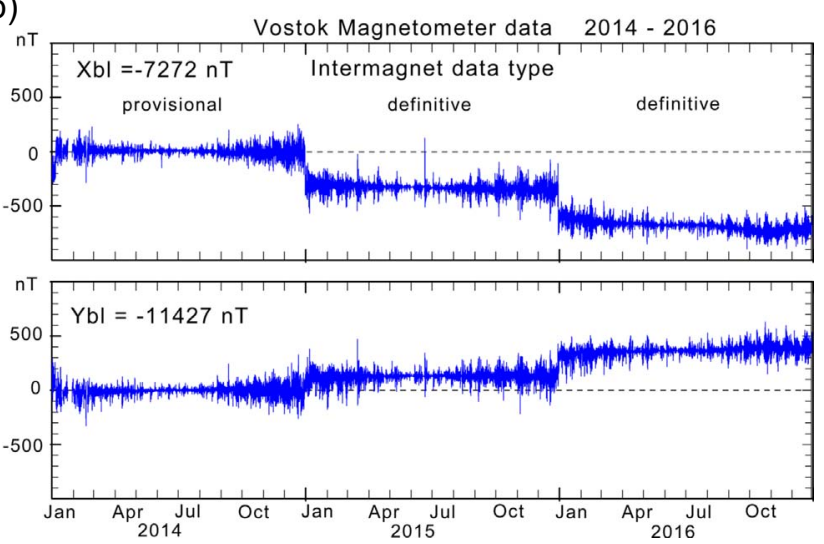

Fig. 3. Display of hourly values of the $X$ and $Y$ components of magnetic data from Qaanaaq (THL) and Vostok (VOS) using fixed base line levels $\left(X_{\mathrm{bl}}, Y_{\mathrm{bl}}\right)$ throughout the 3 years.

problem for the magnetometer data reported to Intermagnet as seen in Figure 3b. Both diagrams use fixed base level values, $X_{\mathrm{bl}}, Y_{\mathrm{bl}}$, throughout the 3 years of displayed data.

As part of the processing prior to PC index calculations, the baseline values have been adjusted to present smooth (secular) variations throughout the span of years included in the epoch from 1992 to 2018. The derived PCN and PCS values have, furthermore, been visually scanned (and compared to each other) in order to detect irregular index behaviour like the erroneous daily excursions in the AARI PCS indices for 2011 seen in Figure 16 here (cf. Stauning, 2018a, 2020b).

Results from the correlations of PC index values in different versions with values of the merging electric field are displayed in Figures 4-6.

The correlation coefficients, Rx, have been derived on a seasonal basis for the display in Figure 4. Spring values plotted at mid-March are the results from successive February, March, and April data and so on. The coefficients for the correlation between PCN and $E_{\mathrm{M}}$ are displayed in blue line, The PCS $E_{\mathrm{M}}$ correlation in red, while the $\mathrm{PCC}-E_{\mathrm{M}}$ correlation coefficients are shown in heavy magenta line. The PCC indices were in most cases derived from Qaanaaq-based PCN and Vostokbased PCS values. For the years 2012 and 2013 where the Vostok data were incomplete, data from Dome-C (DMC) observatory were used to derive an alternative PCS index, here denoted PCD. The correlation between $E_{\mathrm{M}}$ and PCD is displayed in green line, while the correlation between $E_{\mathrm{M}}$ and 

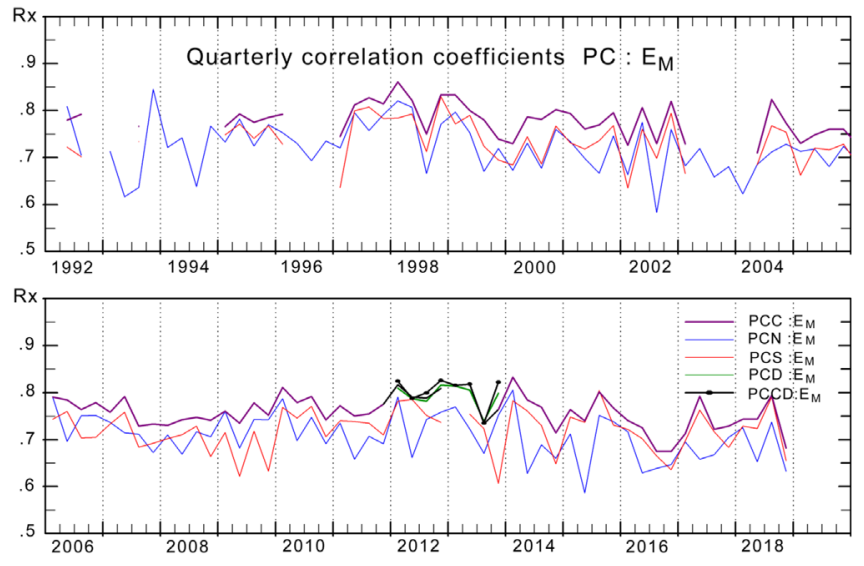

Fig. 4. Correlation of the solar wind merging electric field, $E_{\mathrm{M}}$, with polar cap indices, PCN (blue line), PCS (red), PCC (magenta), PCD (green), and PCCD (black). PCD and PCCD use Dome-C magnetic data.

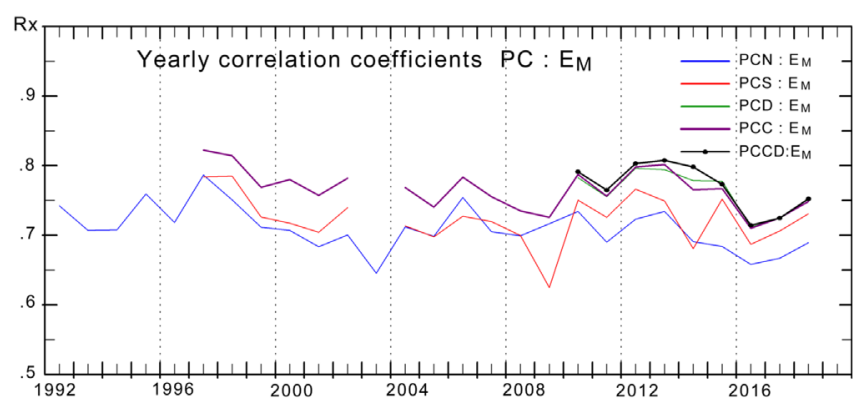

Fig. 5. Yearly averages of correlations between $E_{\mathrm{M}}$ and PCN (blue line), PCS-Vostok (red), PCS-Dome-C (green), PCC-(QaanaaqVostok) (heavy magenta), and PCCD-(Qaanaaq-Dome-C) in heavy black line.

PCC derived by using PCN and PCD values is displayed in heavy black line (PCCD).

It is readily seen from Figure 4 that the correlation between PCC and $E_{\mathrm{M}}$ is significantly higher than the correlation between either of PCN or PCS and $E_{\mathrm{M}}$. It is also seen that the correlation between PCN and $E_{\mathrm{M}}$, in most cases, is lower than the correlation between PCS and $E_{\mathrm{M}}$.

The yearly correlation coefficients are presented in Figure 5. Here, the correlations between PCS indices based on Dome-C data and $E_{\mathrm{M}}$ are displayed for the full range of available data (2010-2018) in the green line while the coefficients for the correlation between PCCD based on PCN-PCD values and $E_{\mathrm{M}}$ are displayed in black line.

Finally, in the series of displays of correlation coefficients, Figure 6 displays the monthly correlation coefficients based on values from the years 1998-2018 except 2003 void of PCS data and 2013 with incomplete PCS data. Values for Dome-C available since mid 2009 only are not included here.

It is seen from Figure 6 that the correlations between PCN and $E_{\mathrm{M}}$ are clearly lower in the northern summer months, MayJuly, than for the rest of the year. Similarly, the correlations between PCS and $E_{\mathrm{M}}$ are clearly lower in the local summer

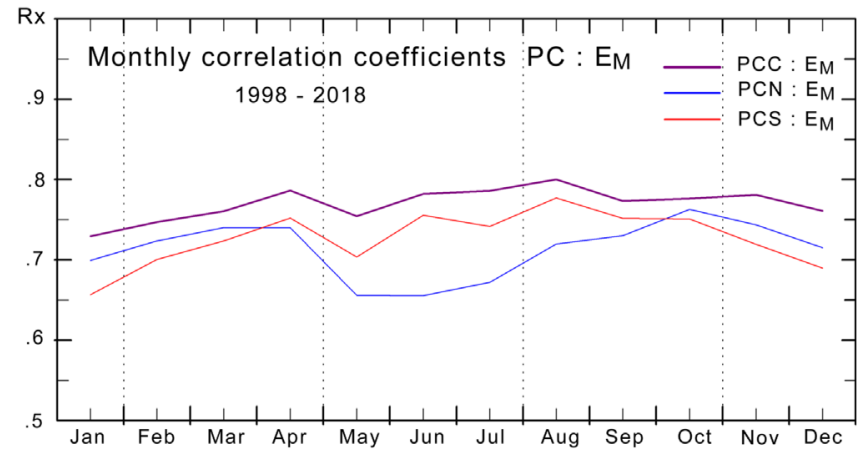

Fig. 6. Display of monthly average coefficients for the correlation between $E_{\mathrm{M}}$ and PCN(blue line), PCS (red), and PCC (magenta).

months, November-January, for Vostok than for the other seasons. Selecting the local winter index, PCW, that is, jumping between the PCN and PCS traces, improves correlation values while selecting the local summer index (PCU) reduces correlations. It is seen that the correlation between PCC and $E_{\mathrm{M}}$ is lowest during the northern winter months (November-January). However, the overall correlation between PCC and $E_{\mathrm{M}}$ is clearly higher throughout all years and all seasons than the correlations between $E_{\mathrm{M}}$ and either of PCN, PCS, PCA (average of PCN and PCS), PCW, and PCU index versions. From Figures 4 and 5 there is a tendency for decreasing correlations between $E_{\mathrm{M}}$ and either of the PC indices with time over the recent years. However, an in-depth investigation of this issue is beyond the scope of the present submission. Correlation coefficient values for the unipolar PC indices and their combinations throughout the available spans of years are displayed in Table 5 of the summary Section 8 .

\section{Relations between the PC and Kp indices}

The added amount of polar magnetic data available now (2020), among other from the Dome-C observatory, compared to the situation in 2007 where the PCC index concept originated (Stauning, 2007), and in 2008 and 2012 where the PCC index concept was further developed (Stauning et al., 2008; Stauning, 2012), makes it worthwhile to re-examine relations between the PCC indices and other ground-based magnetic indices. Here, the mid-latitude $\mathrm{Kp}$ indices and the ring current indices derived from near-equatorial magnetic observations are considered.

The local $\mathrm{K}$ magnetic disturbance indices and, in particular, the planetary $\mathrm{Kp}$ indices are to a large extent used in space weather monitoring and solar-terrestrial research to provide indications of the level of geomagnetic disturbances (Bartels, 1957; Menvielle et al., 2011). A problem for many applications of the $\mathrm{K}$ (and $\mathrm{Kp}$ ) indices is their sparse 3-hour sampling rate. This limited accessibility could be contrasted to the 1-min availability of the PC indices that may provide almost instantaneous indications of the geomagnetic disturbance level. Thus the PC indices might add to the timely surveillance of space weather conditions otherwise provided more sparingly by the $\mathrm{K}$ (and $\mathrm{Kp}$ ) indices. With the PCN and PCS indices, the occasional occurrence of negative values is a conceptual problem since there is no unique relation between their values, when negative, and the $\mathrm{K}$ (or $\mathrm{Kp}$ ) 
(a)

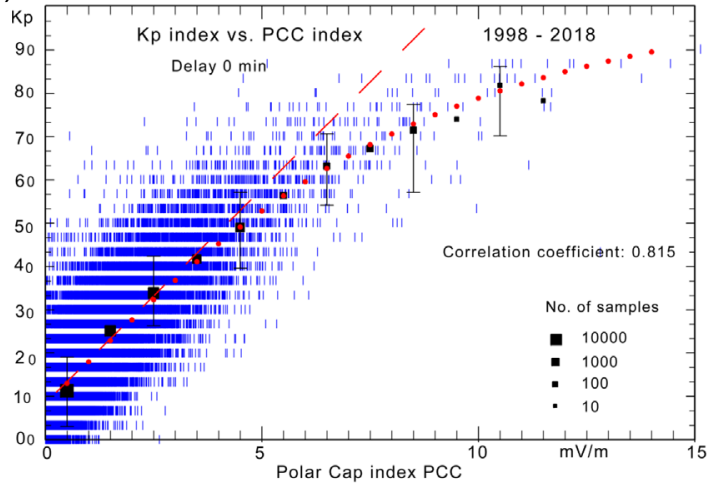

(b)

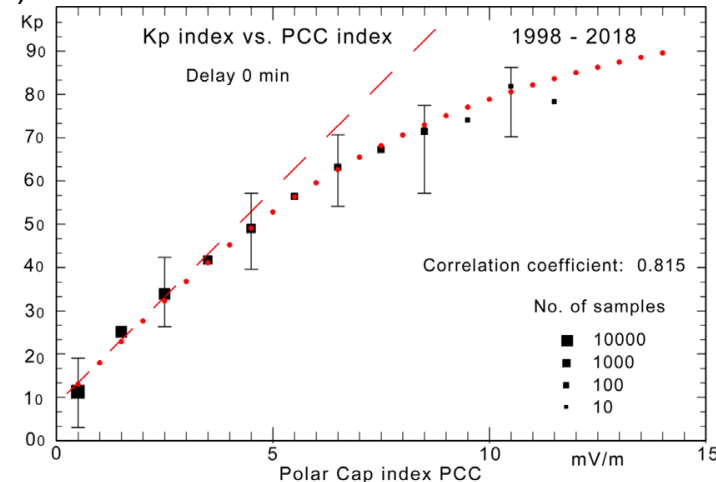

Fig. 7. Relations between Kp and the polar cap PCC indices. (a) Display of all $\mathrm{K}_{\mathrm{P}} \mathrm{PCC}$ samples. (b) Display without samples. The black squares present averages of Kp index values and number of 15-min PCC samples for each unit of PCC while the error bars indicate standard deviation. The dashed line indicates a linear relation while the small red dots indicate a functional relation.

indices. The use of the PCC indices improves the relation making it unambiguous and consistent as shown in Figure 7.

Figures $7 \mathrm{a}$ and $7 \mathrm{~b}$ display the relation between $\mathrm{Kp}$ indices represented on a triple fraction scale $\left(\mathrm{Kp}\left(0_{\mathrm{o}}\right)=0.00, \mathrm{Kp}\right.$ $\left(0_{+}\right)=0.33, \mathrm{Kp}\left(1_{-}\right)=0.67$ and so on) and PCC index values averaged over a 3-hour interval. Figure 7a displays the individual Kp-PCC samples by short bars. The black squares present averages of Kp indices for each unit of PCC with the involved number of 3-h Kp-PCC samples indicated by their size on the lower right scale and with error bars to indicate standard deviation (spread). The red dashed line displays the slope and intercept values derived from linear regression of Kp on PCC (Kp as a function of PCC) with Kp being values on the regression line with slope $S \approx 1.00$ (cf. Table 1). The PCC-based Kp regression line provides a fair approximation up to $\mathrm{Kp} \approx 5$ but clearly fails at larger PCC values.

$$
\begin{aligned}
& \mathrm{Kp}=\mathrm{Kp}_{0}+\mathrm{S} \cdot \mathrm{PCC} \\
& \mathrm{PCC} \text { in } \mathrm{mV} / \mathrm{m}, \mathrm{S}=0.987, \mathrm{Kp}_{0}=0.847 .
\end{aligned}
$$

The small red dots indicate the least squares best fit between the 3-hourly Kp and PCC values and a functional relation of the form:

$$
\begin{aligned}
& \mathrm{Kp}^{*}=\mathrm{Kp}_{0}^{*}+\mathrm{PCC} \cdot\left(1+\left(\mathrm{PCC} / \mathrm{PCC}_{0}\right)^{2}\right)^{1 / 2} \\
& \mathrm{PCC} \text { in } \mathrm{mV} / \mathrm{m}, \mathrm{PCC}_{0}=10 \cdot \mathrm{mV} / \mathrm{m}, \mathrm{Kp}_{0}^{*}=0.80 .
\end{aligned}
$$

The function has no direct physical origin but has been included to illustrate the systematic relation between Kp and PCC including the saturation effects at enhanced disturbance levels. For small PCC values, equations (5) and (6) provide nearly the same results. Equation (6) should be used for calculations of equivalent $\mathrm{Kp}$ indices from observed PCC values in order to avoid unrealistic high $\mathrm{Kp}$ index values above $9_{0}$ for PCC above 8 $\mathrm{mV} / \mathrm{m}$.

The correlation between Kp and PCC for the cases presented in Figure 7 has a value of $\mathrm{Rx}=0.815$ with no delay between the index series. Stepwise shifting the PCC timing up and down (in steps of $2 \mathrm{~min}$ ) has demonstrated that the delay $=0$ provides optimum correlation. The corresponding displays for other PC index versions are shown in Figures 8a-8d while the correlation and regression results are presented in Table 1 . All versions comprise the same number $(53,414)$ of 3 -h samples with the requirement that valid PCN and PCS values should both be present.

It is evident from the displays in Figures 8a-8d that there is a problem with the negative PC index values for the interpretation of the Kp-PC index relations for all the displayed versions. Values of the correlation coefficients and results from the regression based on 3-h samples throughout the epoch 19982018 are shown in Table 1 including the summer selection indices (PCU). For uniformity, all parameters refer to the no-delay cases.

\section{Relations between PCC indices and the ring current indices}

The currents encircling the Earth near equator at distances of typically 4-6 Re could be divided into the symmetrical part (RCS) formed all the way around the Earth, mostly by drifting mirroring energetic electrons and ions, and the partial ring current (RCP) mainly developing at the night side only. The ring current intensities are detected from a network of nearequatorial magnetometer stations and processed at World Data Centre WDC-C2 in Kyoto to provide indices for the symmetrical as well as the partial ring currents (Sugiura \& Kamei, 1981). The hourly average symmetrical deflections scaled from the horizontal $(\mathrm{H})$ components define the Dst indices. The corresponding symmetrical ring current index scaled from 1-min values of the $\mathrm{H}$ and $\mathrm{D}$ components provides the SYM-H and SYM-D indices, respectively. Similarly, the asymmetrical parts of the 1-min $\mathrm{H}$ and D components generate the ASY-H and ASY-D indices.

\subsection{Asymmetrical ring current index, ASY-H}

The asymmetrical ring current indices, ASY-H, are provided by Kyoto WDC-C2 (Iyemori et al., 2000) as 1-min values. For the present statistical study a less detailed time resolution is considered appropriate. Hence, the ASY-H indices and the polar cap indices, PCC, have been averaged to form 15-min samples. 
Table 1. Correlation coefficients and regression results for Kp-PC relations. Epoch 1998-2018.

\begin{tabular}{lcccccrr}
\hline Parameter & PCC & PCN & PCS & PCA $^{1)}$ & PCW $^{2)}$ & PCU $^{3)}$ & $\mathrm{mV}^{3}$ \\
\hline Correlation & 0.815 & 0.758 & 0.770 & 0.797 & 0.795 & 0.736 \\
Slope $(S)$ & 0.986 & 0.813 & 0.843 & 0.903 & 0.902 & 0.764 & $(\mathrm{mV} / \mathrm{m}){ }^{-1}$ \\
Intercept $\left(\mathrm{Kp}_{0}\right)$ & 0.847 & 1.122 & 1.052 & 1.025 & 1.021 & 1.145 \\
\hline
\end{tabular}

1) Average of available PCN and PCS values.

2) Winter values of PCN or PCS index values.

3) Summer values of PCN or PCS index values.
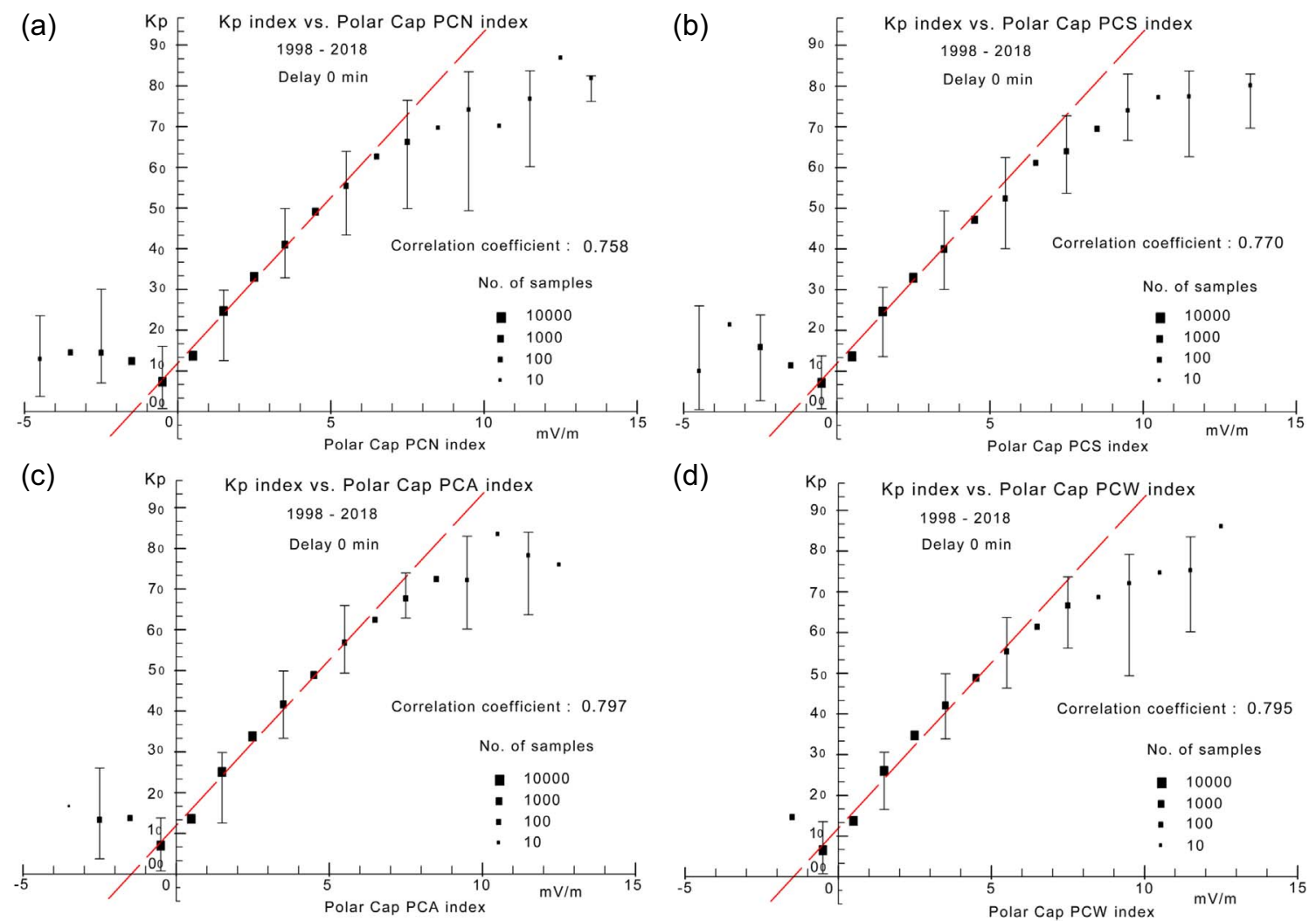

Fig. 8. Display of Kp against PCN (a), PCS (b), PCA (c) and PCW (d) in the format of Figure 7b. The dashed red lines are illustrative only and placed to fit the positive PC index values. Note the upturns for negative PC index values.

The 15-min index data sets have been subjected to linear correlation analyses using a stepwise variable delay between samples of the respective time series assuming that the maximum value of the correlation coefficient provides the most appropriate delay. With this delay imposed on all pairs of samples of the time series, a linear relation between the two parameter sets was found by least squares regression analysis. The average deviation, the average numerical (absolute) deviation, and the RMS standard deviation, were calculated from the assumed linear relations.

The present investigation has considered 4-days intervals from most major geomagnetic storms with Dst(peak) $<-100 \mathrm{nT}$ occurring between 1992 and 2018 with the onset occurring on the first day. Figure 9 displays scatter plots of 15-min ASY-H index values against PCC values. The $8 \mathrm{~min}$ delay noted in the figure was found to provide least RMS deviation and optimum correlation $(\mathrm{Rx}=0.743)$ for 15 -min samples of the two index series. A noteworthy feature in the display is the persistent close linear relations between the average ASY-H values and PCC indices up to high disturbance levels reflected in both indices. The regression and correlation were based on using all available ASY-H - PCC sample pairs (around 30,000). The relation is expressed below:

$$
\mathrm{ASYH}=10.9 \cdot \mathrm{PCC}+16[\mathrm{nT}] .
$$

Studies of the correlation between ASY-H and PC indices may also be used to look at the relevance of further PC index versions in play. It has been claimed (Troshichev, 2017; ISO/ TR/23989, 2020) that either of the unipolar indices with the 
(a)

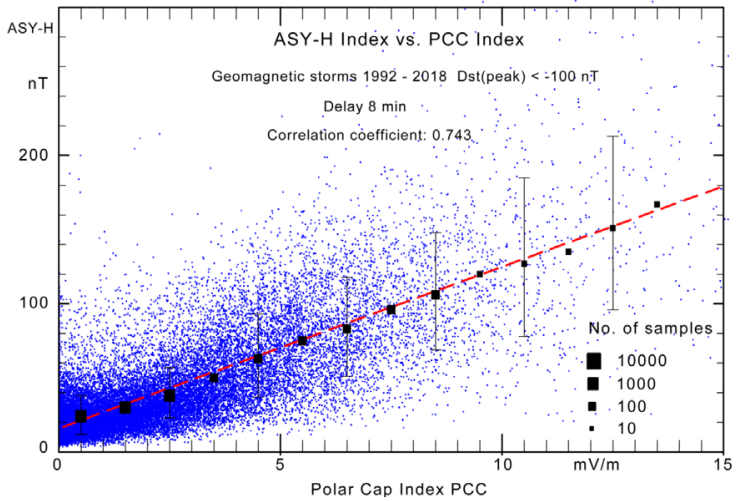

(b)

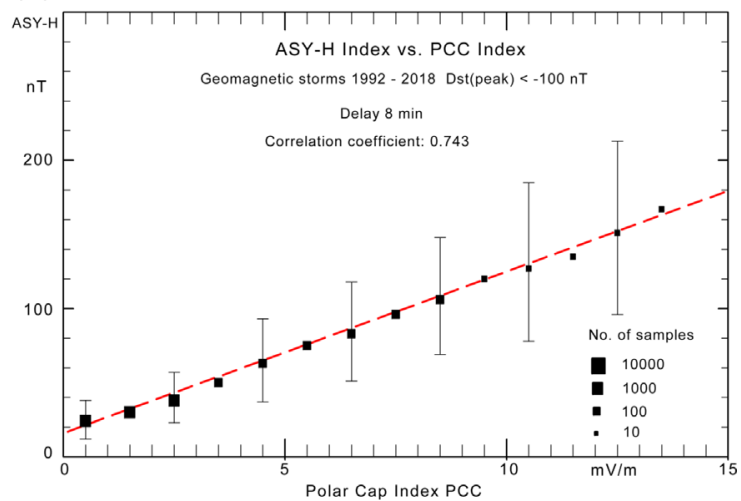

Fig. 9. Scatter plots of ASY-H against PCC index values. (a) Display of individual ASY-H-PCC samples. (b) Display without samples. The black squares indicate average values and number of 15-min samples within each unit interval in PCC, while the error bars at every other unit interval indicate standard deviation. The red dashed lines indicate least squares regression on the 15-min data samples (Eq. (7)). Note the good fit to the interval-average squares.
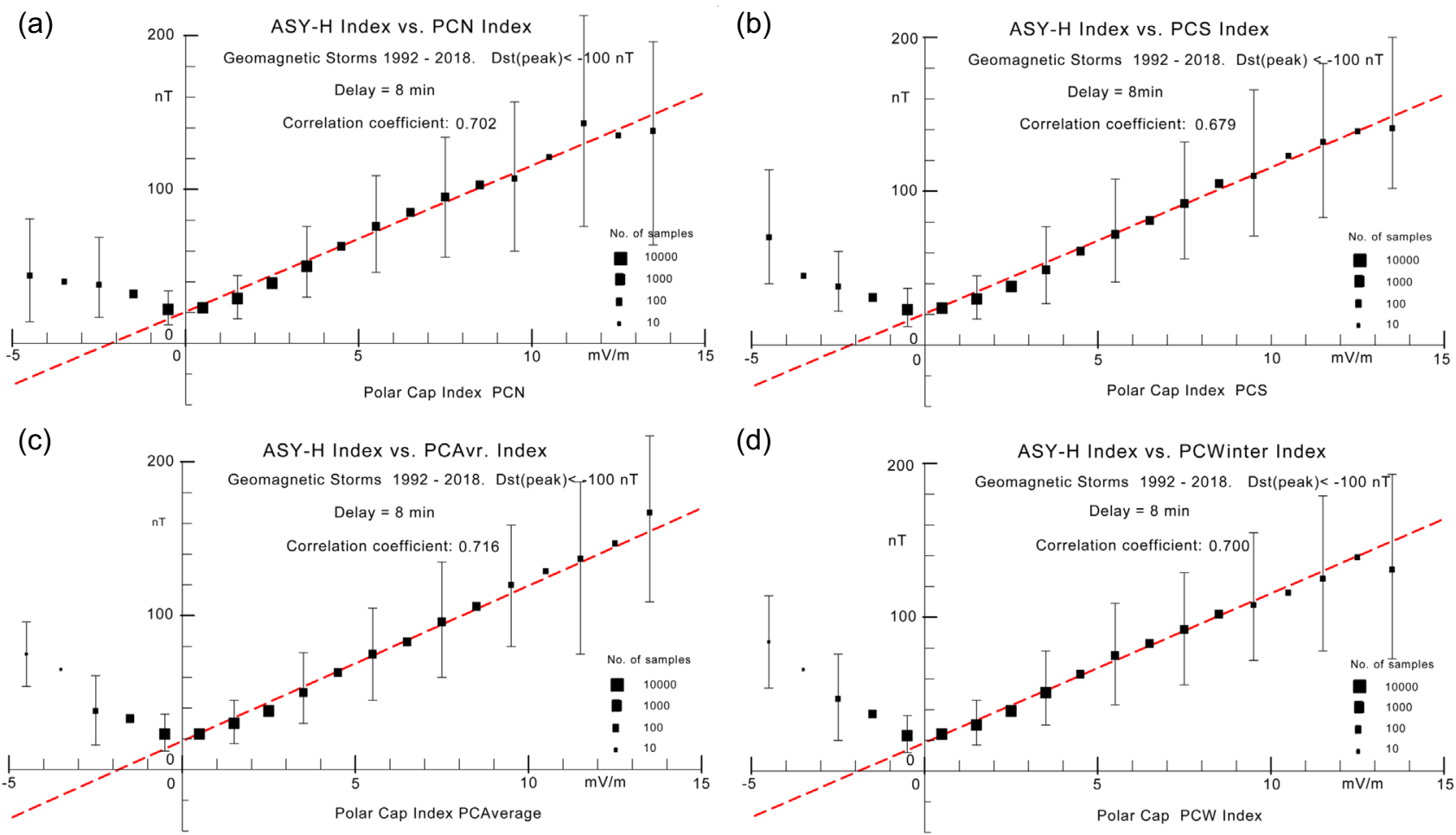

Fig. 10. Displays corresponding to Figure 9b for the relations between ASY-H and PC indices represented by (a) PCN, (b) PCS, (c) PCA (average of PCN and PCS), and (d) winter hemisphere PCW index. The red dashed lines are illustrative only and placed to fit the positive PC index values. Note the upturns for negative PC index values.

adjustments of the reference level (QDC) to include a solar wind sector term would provide an adequate representation of the solar wind effects on the magnetosphere. In further publications, Troshichev et al. (2012) have used the seasonal selections of summer PC indices in their investigations of the relations between PC and ASY-H indices. The results from the examination of the PC-ASY-H relations using the various versions are displayed in the diagrams of Figures 10a-10d and in Table 2.

It should be noted that data for the various versions have been selected from the epoch 1992-2018 on basis of the same criteria (magnetic storm intervals). Hence no effort was made to avoid intervals where data for one or the other index version were missing.

It is readily seen from Figures 10a-10d that the data for the positive averages of index values are well represented by a linear approximation corresponding to equation (7). The problems reside, in particular, with the negative PC index values. While the correlation coefficient for 15-min samples of the PCCASY-H relation in Figure 9 is $\mathrm{Rx}=0.74$, then the correlation between the ASY-H and PC indices for the cases presented in 
P. Stauning: J. Space Weather Space Clim. 2021, 11, 19

Table 2. Number of samples, correlation coefficients, and regression results for ASY-H/PC relations.

\begin{tabular}{lccccccc}
\hline Parameter & PCC & PCN & PCS & PCA & PCW & PCU \\
Samples & 28,803 & 34,839 & 28,802 & 28,880 & 33,728 & 29,913 \\
Correlation & 0.743 & 0.702 & 0.679 & 0.716 & 0.700 & 0.683 \\
Slope & 10.9 & 9.5 & 9.5 & 10.1 & 9.7 & 9.7 & $\mathrm{Un}$ \\
Intercept & 16 & 27 & 27 & 32 & 30 & 20 & $\mathrm{nV} / \mathrm{mV})$ \\
Mean dev. & -1.7 & -0.3 & -0.8 & -0.5 & 0.1 & $\mathrm{n}$ \\
RMS dev. & 23.6 & 24.5 & 25.6 & 24.0 & 24.0 & 25.5 \\
\hline
\end{tabular}

Figures 10a-10d (including summer indices, PCU) are all close to a correlation coefficient value of $\mathrm{Rx}=0.70$. The number of 15-min samples, correlation coefficients and results from the linear regression analyses are summarized in Table 2.

\subsection{Symmetrical 1-min ring current index, SYM-H}

The 1-min symmetrical ring current index, SYM-H, can be exposed to a correlation and regression study equivalent to the study presented in Section 6.1 for the ASY-H index. Results from such studies are displayed in Figure 11 with the delay set to 60 min (PCC leading over SYM-H).

With the SYM-H, contrary to the ASY-H index, the correlation with PCC does not provide a clear maximum, but continues to increase very slowly with increasing delay up to more than 3 hours. With increasing delays, the correlation coefficient increased from $\operatorname{Rx}(0 \mathrm{~h})=0.533$ to $\operatorname{Rx}(1 \mathrm{~h})=0.623, \operatorname{Rx}(2 \mathrm{~h})=$ 0.636 , and $\operatorname{Rx}(3 \mathrm{~h})=0.645$. The explanation is probably that the large PCC values at the start of the events correlate well with large slowly varying SYM-H values recorded through many hours of the continued ring current build-up. Thus, the direct correlation of the symmetrical ring current indices with PC indices is not meaningful beyond the simple conclusion that large PC index values relate to large SYM-H index values.

\subsection{Hourly ring current index, Dst}

The failure of reaching maximum correlation between PCC and the symmetrical 1-min ring current index, SYM-H also includes the Dst hourly ring current index. The approach suggested in Stauning et al. (2008) and Stauning (2012) has been applied instead. Thus, the PCC index is used in a source function to describe the gradient in the Dst index rather than in correlations with its actual value.

The Dst index is considered to represent the energy stored in the ring current. With Dst* being the recorded Dst index corrected for contributions from magnetopause currents (MPC) mostly related to the solar wind dynamical pressure, a relation between the accumulated kinetic energy of the charged particles encircling the Earth and the Dst* index is provided by the Dessler-Parker-Sckopke relation (Dessler \& Parker, 1959; Sckopke, 1966). Following Burton et al. (1975), the rate of change in the Dst* index with time could be written:

$$
\mathrm{dDst}^{*} / \mathrm{d} t[\mathrm{nT} / \mathrm{h}]=Q[\mathrm{nT} / \mathrm{h}]-\mathrm{Dst}^{*}[\mathrm{nT}] / \tau[\mathrm{h}] .
$$

The quantity $Q$ (in $\mathrm{nT} / \mathrm{h}$ ) is the source term while the last term in equation (8) is the ring current loss function controlled by the decay time constant, $\tau$, here measured in hours. For the small actual MPC corrections, the Dst dependent statistical values

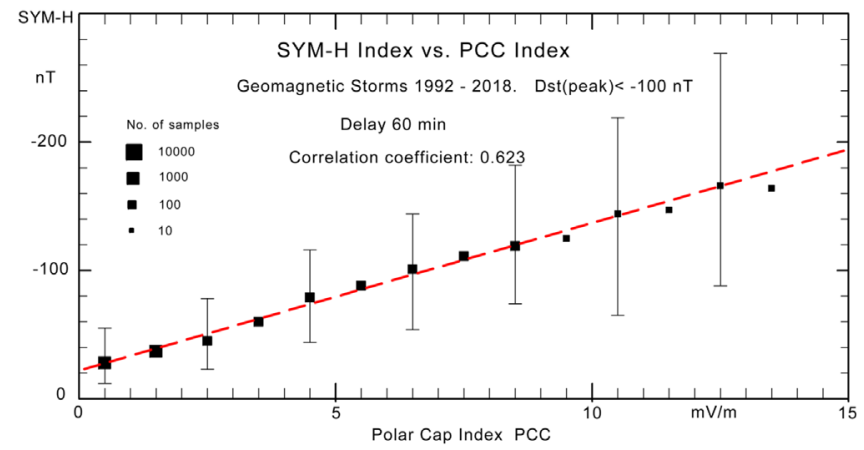

Fig. 11. Scatter plots for SYM-H vs. PCC in the format of Figure $9 b$ with delay $60 \mathrm{~min}$.

provided in Jorgensen et al. (2004) are used here, while the decay function provided by Feldstein et al. (1984) is used for the loss term in the first step. This function uses two decay time constants, $\tau=5.8 \mathrm{~h}$ for large disturbances where Dst $<-55 \mathrm{nT}$, and $\tau=8.2 \mathrm{~h}$ for small disturbances where Dst $>-55 \mathrm{nT}$. Now, the relation in equation (8) has only terms relating to the source function $Q$ and may provide derived Dst index values by integration from a known state, once the source term is defined.

In Burton et al. (1975) the source term $Q$ was related to the $Y_{\mathrm{GSM}}$ component of the solar wind electric field. In the analyses by Stauning et al. (2008) and Stauning (2012), the relations of $Q$ to the polar cap indices were examined for a number of storm event cases during the interval 1995-2002 and 1995-2005, respectively. Here we repeat these analyses using in the first step selected large storm events throughout 1992-2018 in order to improve the statistical basis. In 4-days segments of all selected storm cases with Dst (peak) $<-100 \mathrm{nT}$ and storm onset on the first day, we first derive the temporal change at time $t=T$ in the hourly Dst* index from the hourly values at $t=T-1$ and $t=\mathrm{T}+1[\mathrm{~h}]$ by the simple differential term:

$$
\mathrm{dDst}^{*} / \mathrm{d} t(T \mathrm{~h})=\left(\operatorname{Dst}^{*}(\mathrm{~T}+1 \mathrm{~h})-\mathrm{Dst}^{*}(T-1 \mathrm{~h})\right) / 2 .
$$

In order to derive the source function, $Q$, to be used in equation (8), the average slope values defined by equation (9) are corrected by including the decay term defined above using the current Dst* value at $t=T$. For the amount of archived geomagnetic storm data, the resulting source function, $Q_{\mathrm{OBS}}$, is then related to the $\mathrm{PC}$ indices considered being potential source parameters since they relate to the interplanetary electric field albeit in the Kan \& Lee (1979) version and not the $Y_{\mathrm{GSM}^{-}}$ component used by Burton et al. (1975). Variable positive or negative delays were imposed on the relation. The PCC indices 


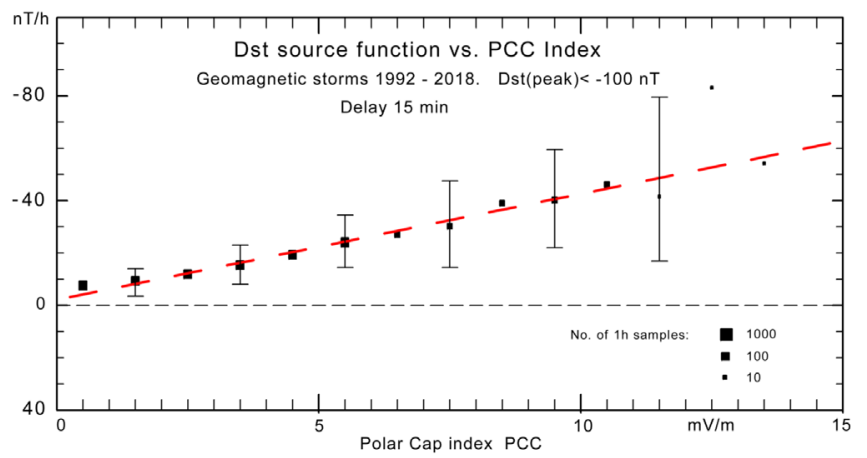

Fig. 12. Scatter plot of $d(D s t *) / d t$ corrected for decay vs. polar cap PCC index. The black squares represent bin-average values and no of hourly samples while the error bars in every other bin represent standard deviation among samples.

are provided here at a more detailed time resolution $(5 \mathrm{~min})$ than the hourly source function values. By shifting the averaging interval by delays varying on a 5-minute scale, hourly averages of the parameters are correlated with the hourly source function values to derive the delay that produces the maximum correlation through the ensemble of storm events. With this delay the best fit linear relation between the source function values and the relevant source parameter is determined by the linear regression analysis illustrated in Figure 12.

In Figure 12, hourly values of dDst*/d $t$ corrected for decay have been plotted against the related PCC index values. Average values within each unit of PCC are displayed by the black squares with sizes corresponding to the number of hourly samples according to the lower right scale.

The scatter plot in Figure 12 presents the Dst* source function, $Q_{\mathrm{OBS}}$, based on observed hourly Dst values corrected for decay (Feldstein et al., 1984) plotted against the polar cap index, PCC, considered to be a potential source parameter. The relation between the best fit source function, $Q_{\mathrm{OBS}}$, and the source parameter values, PCC, is then expressed in a linear function. From the present data set (98 storm periods 1992-2018) we obtain by regression on the total amount of hourly samples:

$$
\begin{aligned}
Q_{\mathrm{OBS}}[\mathrm{nT} / \mathrm{h}]= & -4.1[(\mathrm{nT} / \mathrm{h}) /(\mathrm{mV} / \mathrm{m})] \\
& \cdot \operatorname{PCC}[\mathrm{mV} / \mathrm{m}]-2.2[\mathrm{nT} / \mathrm{h}] .
\end{aligned}
$$

Further versions of the analysis displayed in Figure 12 have been performed with stepwise variable delays to reach an optimum correlation $R=0.668$ at a delay of $\Delta T=15$ min with PCC leading.

This result is close to the corresponding source function $(Q=-4.6 \times$ PCC -1.2$)$ defined in Stauning (2012) from a smaller amount of data (storm events 1995-2005).

With continuous time series of the PCC-based source values, and specification of the relational constants and initial Dst values, it is now possible, at least in principle, to integrate equation (8) to derive values of an "equivalent" Dst index, Dst $_{\mathrm{EQ}}$, throughout any interval of time. The present work has brought the analysis of the relations between Dst and the polar cap index, PCC, important steps forward compared to Stauning (2012) by including a close examination of the Feldstein et al. (1984) decay time constants $(\tau=5.8 \mathrm{~h}$ and $\tau=8.2 \mathrm{~h})$ and their turning level (Dst, lim $=-55 \mathrm{nT})$, and other parameters of importance for the relations between Dst and its possible source functions, primarily the PCC index. A further parameter introduced here is the optimum delay between samples of the PCC time series and the calculated Dst values. For these cases, the PCC-based index values lead by a few $(\approx 45)$ minutes.

In addition to the decay time constants (Feldstein et al., 1984) and delays, the examination has included the impact from the saturation of the PC indices for high levels of the merging electric field (e.g., Stauning, 2018a). In Figures 13a and 13b the individual 15-min samples are displayed by the small blue dots. Bin-average values are displayed by the black squares sized to indicate the number of 15-min samples on the lower right scale. Error bars display standard deviation. The dashed red line indicates equality between PCC and $E_{\mathrm{M}}$.

Figure 13a indicates that the PC indices saturate at high levels of $E_{\mathrm{M}}$. The systematically positioned red dots display a functional relation between PCC and $E_{\mathrm{M}}$ regulated by the asymptotic parameter, $E_{0}$ derived by least squares regression between interval-average values (black squares) and the regression curve (Stauning, 2012):

$$
\mathrm{PCC}=E_{\mathrm{M}} \cdot\left(1+\left(E_{\mathrm{M}} / E_{0}\right)^{2}\right)^{-1 / 2} .
$$

Note that this functional relation is just used for visual indication of the saturation problem.

In a crude approximation for the parameter iteration process, the effective PCC indices $\left(\mathrm{PCC}_{\text {eff }}\right)$ are set equal to the $E_{\mathrm{M}}$ values up to a turning level $\left(\mathrm{PCC}_{\mathrm{lim}}\right)$ at around $5 \mathrm{mV} / \mathrm{m}$ and then forced to deviate by adding a linear relation with slope $(S)$ less than unity. The approximation is defined by the two-step linear relation in equations below:

$$
\mathrm{PCC}=E_{\mathrm{M}} \quad \text { for } \mathrm{PCC}<\mathrm{PCC}_{\lim }\left(\mathrm{PCC}_{\lim }=E_{\mathrm{Mlim}}\right)
$$

and

$$
\mathrm{PCC}=E_{\mathrm{Mlim}}+S \cdot\left(\mathrm{E}_{\mathrm{M}}-E_{\mathrm{Mlim}}\right) \quad \text { for PCC }>\mathrm{PCC}_{\mathrm{lim}} .
$$

Conversely, an "effective" PCC index could be defined to provide a value equivalent to $E_{\mathrm{M}}$ in its effect on the energy transfer to the magnetosphere by equations below:

$$
\mathrm{PCC}_{\text {eff }}=\mathrm{PCC} \text { for } \mathrm{PCC}<\mathrm{PCC}_{\text {lim }}
$$

and

$$
\begin{aligned}
& \mathrm{PCC}_{\text {eff }}=\mathrm{PCC}+(1 / S-1) \times\left(\mathrm{PCC}-\mathrm{PCC}_{\text {lim }}\right) \\
& \quad \text { for } \mathrm{PCC}>\mathrm{PCC}_{\text {lim }}
\end{aligned}
$$

where $S_{\text {eff }}=1 / S-1$ is less than unity.

The black dashed line in Figure 13a displays equations (12a) and (12b) with $E_{\mathrm{M}_{\text {lim }}}=5 \mathrm{mV} / \mathrm{m}$ and $S=0.63$ while Figure 13b displays the individual and average PCC values as well as the fitted function modified by equations (13a) and (13b) with $E_{\mathrm{M}_{\text {lim }}}=\mathrm{PCC}_{\text {lim }}=5 \mathrm{mV} / \mathrm{m}$ and $S_{\text {eff }}=0.60$.

A test bed to handle multiple parameter adjustments is provided by the above-mentioned set of 98 magnetic storms with peak Dst below $-100 \mathrm{nT}$ occurring throughout the epoch from 1992 to 2018 where PCS indices are available (with some gaps). For calculation of PCN indices, Qaanaaq (THL) data are virtually continuously available since 1975 . Vostok magnetic data were not available for PCS calculations during most of 
(a)

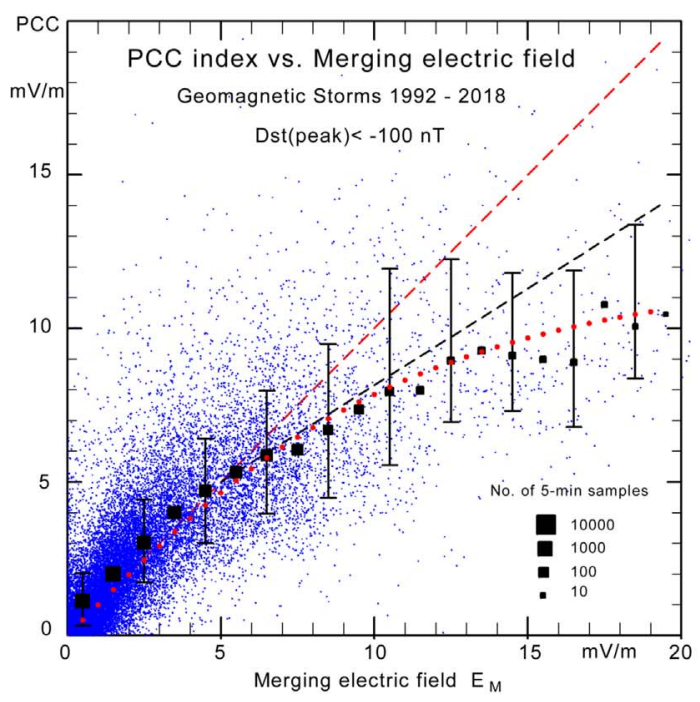

(b)

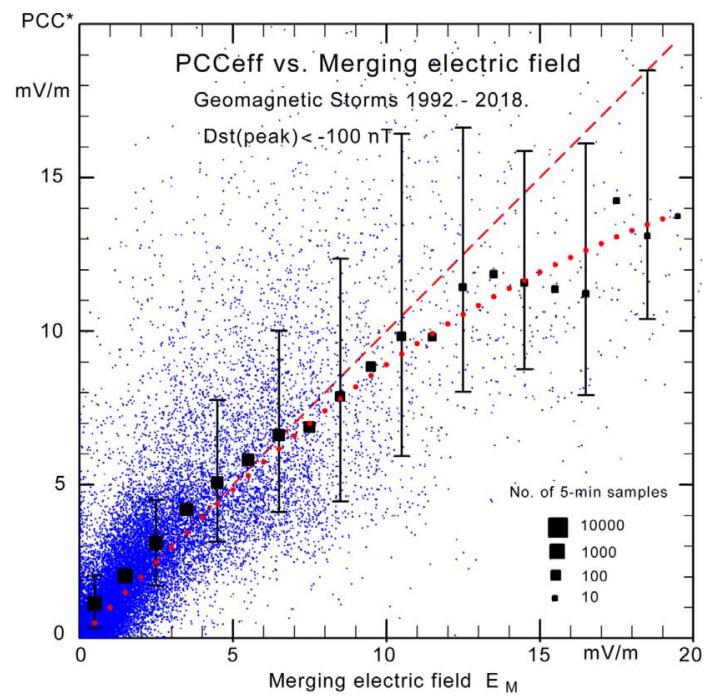

Fig. 13. (a) Relations between the merging electric field, $E_{\mathrm{M}}$, and the polar cap, PCC, index. The small blue dots display the individual 15 -min samples. The larger black squares with error bars show the bin-average values and sample numbers. The dashed red line indicates equality while the red dots display a functional relation between $E_{\mathrm{M}}$ and PCC. The dashed black line indicates a PCC modification (b) Same data set but with the modified PCC values (PCCeff) displayed against $E_{\mathrm{M}}$.

1993 and 1996, all of 2003, and parts of 2012 and 2013. Dome-C magnetic data have been substituted for missing or unreliable Vostok data for PCS calculations throughout 2012 and 2013. For each storm event a sequence of 4 days is considered with the storm starting on the first day. Starting on the initial values defined in Feldstein et al. (1984), the parameters have been changed in small successive step searching for maximum correlation and minimum deviations.

Examples of observations-based and equivalent Dst values are displayed in Figures 14a and 14b. For these cases the integration of the source term has been started at the real Dst value and then allowed to proceed independently throughout the 4 days in each set.

The examples in Figures 14a and 14b represent cases of good correlation $(\mathrm{Rx}=0.957)$ and poor correlation $(\mathrm{Rx}=$ $0.762)$ compared to the average correlation level $(\mathrm{Rx}=0.810$, cf. Table 4). Note also in Figure 14b the intervals of strongly negative PCN values which, if included, would decrease the correlation between the published (real) Dst and the PCC-based Dst $_{\mathrm{EQ}}$ values considerably. A further feature of Figure $14 \mathrm{~b}$ is the effects of the strong storm sudden commencement (SSC) at 15 UT on 22 June 2015. The SSC event not included in the Dst modelling counteracts the PCC effects and prevents Dst from reaching the negative peak value displayed by the Dst $_{\mathrm{EQ}}$ course.

Figures 14a and 14b indicate good and fair agreement, respectively, between the observed and the equivalent Dst values. Generally, the agreement is best for moderate storms. Going from the moderate to the strong storm cases gives sometimes less agreement between real Dst values and equivalent PCC-based Dst $\mathrm{EQ}_{\mathrm{EQ}}$ values, possibly related to saturation effects not compensated for by the PCC modifications defined in equations (12a), (12b) and (13a), (13b). For the very weak cases the uncertain effects from magnetopause currents (MPC), although small, may have relatively large effects. (a)

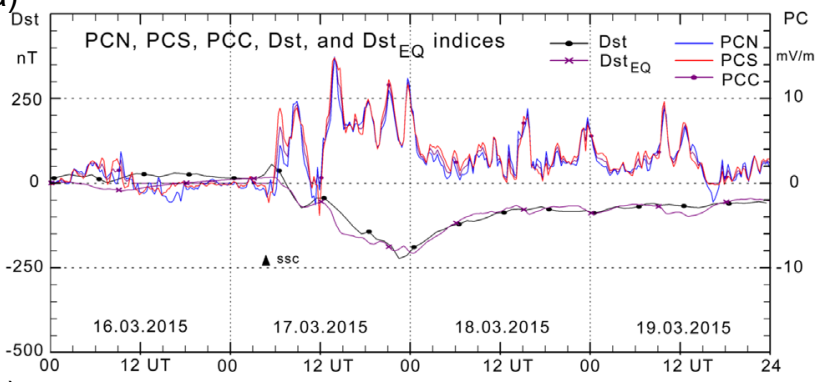

(b)

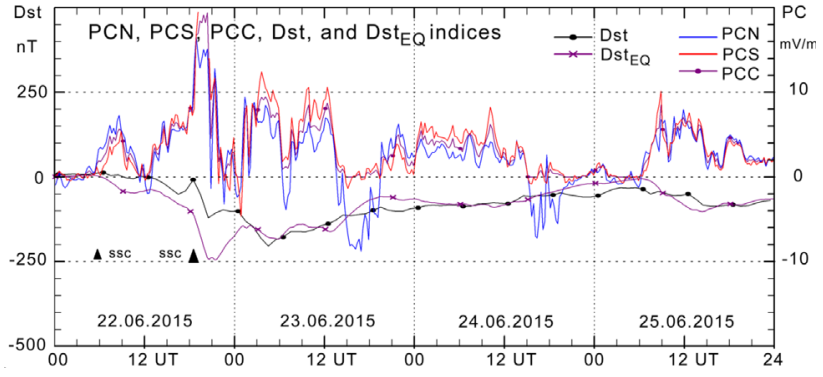

Fig. 14. (a, b) Examples of published (real) Dst (black line, dots) and equivalent Dst (magenta, crosses) values calculated from the PCCbased source function. Values of PCC (magenta), PCN (blue), and PCS (red) are displayed in the upper fields on the right scale.

With the understanding of the effects of adjustments of the various parameters gained from the test bed exercises, the full range of available data has been used to integrate the PCCbased source function throughout 1992-2018 to derive equivalent Dst $_{\mathrm{EQ}}$ values without attachment at all to the published (real) Dst values. In the first step, the timing parameters have been adjusted to provide the overall best correlation and least 
deviations. In the second step, the PCC high-level modification suggested in equations (13a) and (13b) has been used to provide the best possible agreement between peak values of Dst $_{\mathrm{EQ}}$ and Dst keeping the other parameters near their initial values.

The resulting iterated optimum parameters are presented in Table 3 along with the original values used in Stauning (2012) while Table 4 presents the resulting quality control results. The iterations gave slightly different parameters depending on which of quality parameters being considered in the process. Thus, the parameter values of Table 3 are not unique but present compromises.

The calculated Dst $\mathrm{EQ}_{\mathrm{EQ}}$ values are based on integration of the source function defined from the PCC indices. In cases where either PCN or (Vostok or Dome-C-based) PCS values were unavailable, the available hemispherical PC indices were used for PCC. The derived $\mathrm{Dst}_{\mathrm{EQ}}$ values have been displayed in plots along with the real Dst values throughout the entire epoch for control of the calculations. These plots are presented in the Appendix. Examples for the stormy years 2001 and 2015 are displayed in Figures 15a and 15b.

Figures $15 \mathrm{a}$ and $15 \mathrm{~b}$ display close, although not perfect, matches between the real Dst values (blue line) based on observed near-equatorial magnetic variations and the equivalent Dst $_{\mathrm{EQ}}$ values (magenta line) calculated by integration of the PCC-based source function (Eq. (8)) using the parameters from Table 3 including high-level modifications of the PCC indices. The integration was performed in steps of 5 min starting from Dst $_{\mathrm{EQ}}=0$ on 1 January 1992 .

In Tables 3 and 4 the column "Fldst. PCC" relates to the Dst $_{\mathrm{EQ}}$ calculations using the control parameters from Feldstein et al. (1984) presented in Stauning (2012) and used with the PCC-based source function. The columns "Test bed" refer to the selection of 98 major storm event periods (Dst(peak) <-100 nT), while the "Optimal" columns refer to the total 1992-2018 sequence.

\section{Discussions}

\subsection{Correlation techniques}

In the present manuscript, all correlations are made by using the linear product-moment formula. Most regression calculations are made by applying linear least squares regression using the basic sample types considered most useful for the purpose. For the correlation and regression calculations for PC indices against solar wind parameters and global magnetic disturbance indices, 1-min data samples are available. However, it is believed that the faster variations (1-min samples) are not transferred systematically between the solar wind and the polar ionosphere or between the polar cap and the ring current regimes. Thus, 15-min average values were used for PC- $E_{\mathrm{M}}$, PC-ASY-H, and PC-SYM-H relations. The PC index data were first converted from 1-min to 5-min average samples by removing the max and min values for spike suppression. Next 15-min averages were formed assuming that spike suppression has been applied to the other parameters by the index suppliers.

The correlations displayed in Figures 4-6 and the correlation coefficients presented in Table 5 are based on forming summary terms over all samples of the specific seasons, years and calendar months.
Table 3. Parameters for Dst $\mathrm{EQ}_{\mathrm{E}}$ calculations.

\begin{tabular}{lcccc}
\hline Symbol & Fldst. PCC & Test bed & Optimal all & Unit \\
\hline Fast decay, $\tau 1$ & 5.8 & 6.5 & 5.5 & $\mathrm{~h}$ \\
Slow decay, $\tau 2$ & 8.2 & 7.0 & 7.0 & $\mathrm{~h}$ \\
DstX level & -55 & -70 & -52 & $\mathrm{nT}$ \\
Dst gradient & -4.6 & -4.5 & -4.5 & $(\mathrm{nT} / \mathrm{h}) /(\mathrm{mV} / \mathrm{m})$ \\
PCC $_{\text {lim }}$ & - & 5.0 & 5.0 & $\mathrm{mV} / \mathrm{m}$ \\
PCC $_{\text {slope }}, S_{\text {eff }}$ & - & 0.40 & 0.60 & - \\
Delay Dst $_{\mathrm{EQ}}-$ Dst & 0 & 45 & 45 & $\mathrm{~min}$ \\
\hline
\end{tabular}

Table 4. Results from Dst ${ }_{\mathrm{EQ}}$ calculations.

\begin{tabular}{lcccc}
\hline Result term & Fldst. PCC & Test bed & Optimal & Unit \\
\hline Mean Dst & -13.08 & -58.2 & -13.08 & $\mathrm{nT}$ \\
Mean Dst & -15.90 & -58.1 & -13.09 & $\mathrm{nT}$ \\
Mean diff. & -2.83 & -0.11 & -0.01 & $\mathrm{nT}$ \\
Abs. diff. & 9.37 & 23.12 & 8.88 & $\mathrm{nT}$ \\
RMS diff. & 12.83 & 28.81 & 12.30 & $\mathrm{nT}$ \\
Correlation & 0.849 & 0.810 & 0.856 & \\
\hline
\end{tabular}

For the PC-Kp correlations, samples were formed by averaging PC indices over every time-shifted 3- h Kp interval. Correlations and linear regressions were applied to these samples. For use in text books' standard formulas for correlation and regression, the summation terms, typically, have the form shown here for the Kp-PC cross products:

$$
\begin{gathered}
\Sigma X Y=\Sigma \quad \Sigma \quad \Sigma K \operatorname{Kp}(n 3 h, \text { nd, ny }) \times P C_{\text {AVR }}(\mathrm{n} 3 \mathrm{~h}, \text { nd }, \text { ny }) \\
\text { ny }=1998-2018 ; \text { nd }=1-365 ; \mathrm{n} 3 \mathrm{~h}=1-8 .
\end{gathered}
$$

With this formulation the total number of $\mathrm{Kp}$-PC samples is: $N=20$ years/epoch $\times 365.25$ days/year $\times 83$-h-intervals/day $=$ 58,440 samples. The interval-average numbers of these samples are implemented in the sizes of the black squares referring to the lower right (logarithmic) scale. Thus, the interval-average squares display the general features of the relations and their sizes are important for understanding the illustrations although they are not used in the correlation and regression calculations.

In order to provide closer relations at higher levels in spite of saturation effects, a special functional relation between PCC and $\mathrm{Kp}$ was formed by least squares regression applied between the $3-\mathrm{h} \mathrm{Kp}$ and PCC samples using the function defined in equation (6). This functional relation is not possible for the other index versions due to the occurrences of negative index values. A similar non-linear functional relation is formed between PCC and $E_{\mathrm{M}}$ by equation (11) but only used for illustration of saturation effects in Figures 13a and 13b.

For the ring current (Dst) relations an initial PCC-based source function was defined from regression between hourly averages of (time-shifted) PC indices and hourly differentials of (real) Dst values. At a later stage correlation and regression calculations were based on using real Dst values versus equivalent Dst ${ }_{\mathrm{EQ}}$ values formed by integration of the PCC-based source function over one hour at a time. 
(a)

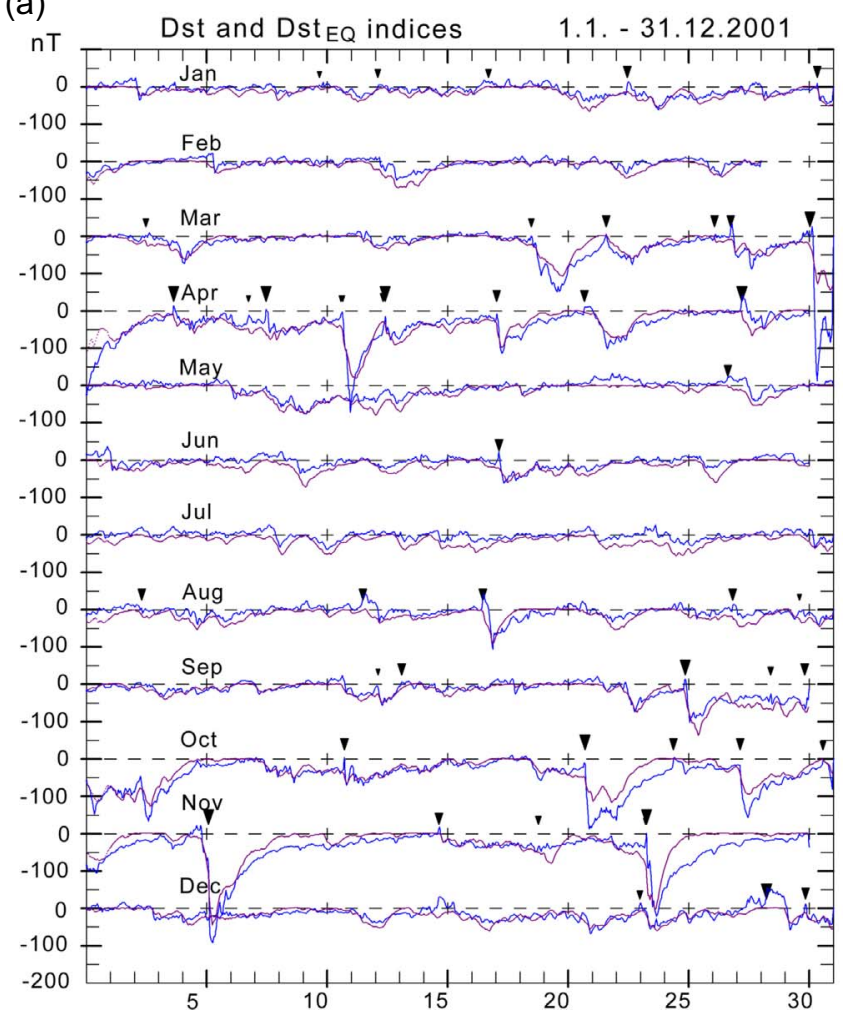

(b)

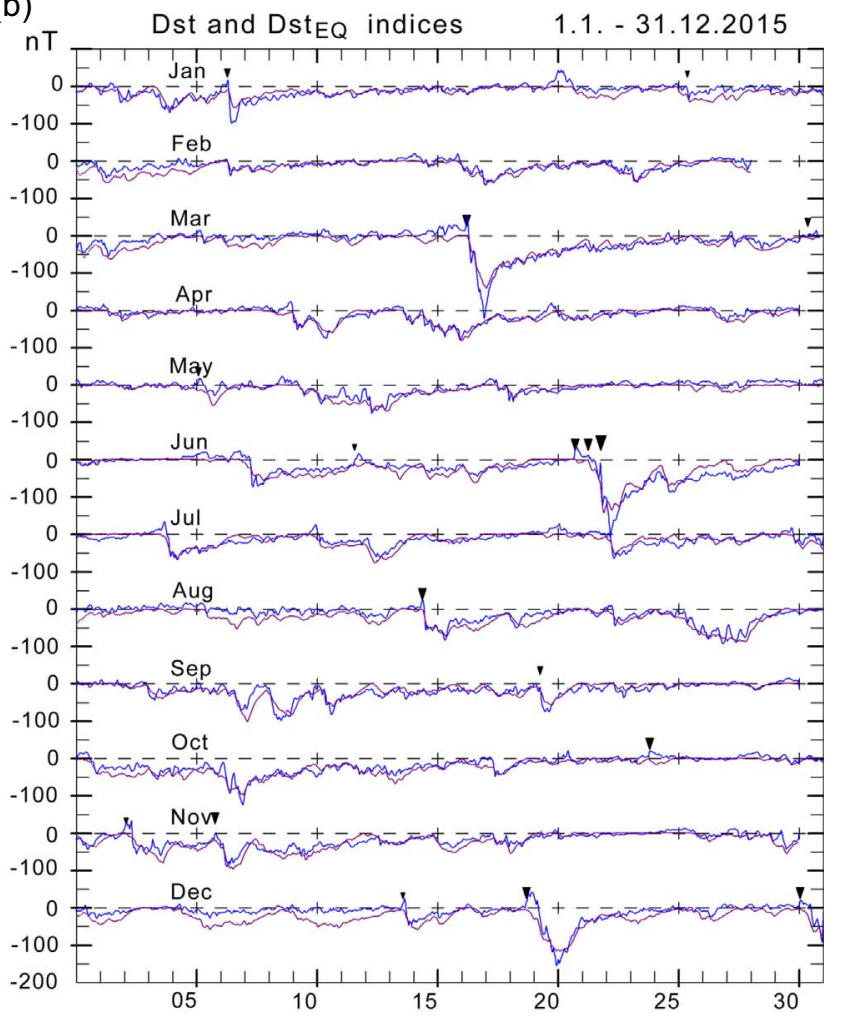

Fig. 15. Observed Dst values (blue line) and calculated Dst $\mathrm{EQ}_{\mathrm{E}}$ values (magenta) for (a) 2001 and (b) 2015. Storm Sudden Commencement (SSC) events are displayed by the downward pointing black triangles to indicate times and sized to indicate their amplitudes.

\subsection{Forward vs. reverse convection conditions}

The present work is focused on discussions of the statement in Resolution no. 3 (2013), that IAGA is "considering that the Polar Cap (PC) index constitutes a quantitative estimate of geomagnetic activity at polar latitudes and serves as a proxy for energy that enters into the magnetosphere during solar wind-magnetosphere coupling".

The statement is based on the close relation between the solar wind merging electric field parameter $\left(E_{\mathrm{M}}\right)$ and $\mathrm{PC}$ index values as well as the association between PC index levels and various energy dissipation processes like auroral activity and building ring currents (Janzhura et al., 2007; Troshichev et al., 2011b, 2014; Troshichev \& Janzhura, 2012; Troshichev \& Sormakov 2015, 2018, 2019; ISO/TR/23989, 2020). However, in these associations the occurrences of negative PC index cases are usually ignored and left out without further reasoning.

However, a fundamental issue for the Polar Cap index concept is the realization that the antisunward transpolar forward convection mode (DP2) at southward IMF is fundamentally different from the reverse convection mode (DP3) associated with northward IMF with respect to the source parameters in the solar wind and also with respect to the impact on the global level of geomagnetic activity. In the forward convection cases (positive PC indices) the disturbance level rises with increasing values of the merging electric field that controls the input of solar wind energy at the front of the magnetosphere. In these cases the PC indices track the merging electric field values. However, as the IMF turns northward (positive $B_{Z}$ )
Table 5. Correlation coefficients for epoch 1998-2018 (ex. 2003 and 2013). The PCC correlation values are emphasized.

\begin{tabular}{lcccccc}
\hline Correlation & PCC & PCN & PCS & PCA $^{1)}$ & PCW $^{2)}$ & PCU $^{3)}$ \\
\hline$E_{\mathrm{M}}$ & $\mathbf{0 . 7 7 0}$ & 0.708 & 0.725 & 0.755 & 0.738 & 0.697 \\
$\mathrm{Kp}$ & $\mathbf{0 . 8 1 5}$ & 0.758 & 0.770 & 0.797 & 0.795 & 0.736 \\
$\mathrm{ASY}-\mathrm{H}^{4)}$ & $\mathbf{0 . 7 4 3}$ & 0.702 & 0.679 & 0.716 & 0.700 & 0.683 \\
\hline
\end{tabular}

1) Average of PCN and PCS.

2) Selection of winter hemisphere PC indices.

3) Selection of summer hemisphere PC indices.

4) Magnetic storm events (1992-2018).

the transpolar convection may turn sunward (reverse) whereby the PC indices may reach large negative values that could not possibly keep any proportionality with the decreasing but still positive merging electric field values. A characteristic case of northward turning IMF, small $E_{\mathrm{M}}$ values, and large negative $\mathrm{PCN}$ values is displayed in Figure 1. Figures $2 \mathrm{a}$ and $2 \mathrm{~b}$ show that reverse convection intensities amount to around $3 \%$ of the forward convection intensities for Vostok (PCS) and 10\% for Qaanaaq (PCN) on the average, while at daytime in the summer season the relative amount may rise to $6 \%$ for Vostok and up to $25 \%$ for Qaanaaq.

These differences between DP2 and DP3 cases were not implemented in the initial DMI version developed by Vennerstrøm (1991), or in the various versions developed at AARI by Troshichev et al. (1988, 2006), Janzhura \& Troshichev (2011), Troshichev \& Janzhura (2012), Troshichev (2011, 2017). 
The differences were also not implemented in the version (Matzka, 2014) submitted jointly from AARI and DTU Space for endorsement by IAGA and granted by Resolution no. 3 (2013) against prior objections by Stauning (2013b).

In recognition of the differences between forward and reverse convection modes, Stauning (2007) brought forward the PCC index concept and also developed new calculation schemes for derivation of PCN and PCS scaling parameters $(\varphi, \alpha, \beta)$ as reported in Stauning et al. (2006), and Stauning (2013a, 2016). In the selection of samples from the epoch used for calculation of PC index scaling parameters, cases of strong northward IMF (NBZ) conditions were omitted. The derivation of the optimum angle $(\varphi)$ becomes more focused on forward convection as the samples are no longer switched between forward and reverse convection cases. The slope values $(\alpha)$ from the regression become less steep by avoiding the samples of large negative values of the projected horizontal disturbance vector $\left(\Delta F_{\text {PROJ }}\right)$ associated with small positive values of the merging electric field $\left(E_{\mathrm{M}}\right)$ at NBZ conditions. The intercept values $(\beta)$ become less negative (see Stauning, 2013a, 2015).

The relative frequency of reverse convection cases is highest in the daytime hours of the summer season as demonstrated in Figures $2 \mathrm{a}$ and $2 \mathrm{~b}$. When reverse convection cases are included, then the adverse effects on the calculations of scaling parameters cause, among others, uneven daily and seasonal relations between PC index values and values of $E_{\mathrm{M}}$. The effects are particularly evident by the low values and early saturation of summer daytime PC index values for high $E_{\mathrm{M}}$ levels seen at the Vennerstrøm (1991) PCN version as well as in the AARI and IAGA-endorsed versions (see, Stauning, 2015, 2018a).

In addition to differences in the calculation of PC index scaling parameters, the definition of the reference level, from which the magnetic disturbance values involved in calculations of the PC indices are measured (cf. Sect. 2), also differs between the IAGA-recommended PC index derivation methods (Janzhura \& Troshichev, 2011; Troshichev, 2011; Matzka, 2014; Nielsen \& Willer, 2019) and the method (Stauning, 2011) applied to derive reference levels ("QDC"s) for calculations of the indices considered here. These differences are elaborated in Stauning (2020b).

The differences between the IAGA-recommended PC index calculation methods and the methods applied here, however, have relatively small impacts on the principal features of the issues presented here. Regardless of the applied derivation methods the PCN and PCS indices, and also their means as well as the summer or winter hemisphere indices do take negative values that correlate poorly with the non-negative values of the merging electric field, $E_{\mathrm{M}}$. Figures 4-6 document clearly that the PCC index values correlate considerably better with the $E_{\mathrm{M}}$ values than either of the individual PCN and PCS indices and their mean or seasonal selections. The good results from using $\mathrm{PCC}$ indices in ring current mapping further supports the concept of PCC indices being the optimum choice for estimates of solar wind energy input. With the possibility of using data from Dome-C for useful PCS indices and Resolute Bay data for PCN indices (Stauning, 2018a,b), the availability of useful PCC index series is greatly improved. Since 2009 and up to present (2020) there is hardly any interval without useful PCC index values.

\subsection{PC indices and the mid-latitude Kp indices}

The local K-indices and, in particular, the Kp indices based on geomagnetic observations from a global array of distributed low- to midlatitude observatories, respond to a wide range of geomagnetic disturbances. Such disturbances may originate from solar flare flashes, solar wind pressure impulses, IMF irregularities, auroral activity such as substorms, and ring current changes. The major sources are also reflected in the $\mathrm{PC}$ indices, which is the basis for the rather close correlation between Kp and PC indices demonstrated in Section 5. Thus, the PC indices in their 1-min sampling rate could be used to supplement the 3-hourly $\mathrm{Kp}$ indices to create a more timely monitoring of geomagnetic disturbances.

In general, the $\mathrm{Kp}$ values increase with increasing $\mathrm{PC}$ index values. However, in contrast to the non-negative PCC indices, the negative PCN or PCS index values cause problems (at least conceptual) since the associated $\mathrm{Kp}$ index values may rise with numerically increasing negative PC index values. In addition, the correlation of Kp with PCN and PCS indices is inferior to the correlation demonstrated with the PCC indices. All PC index versions have serious misfits at high levels in their linear translation like equation (5) to become equivalent $\mathrm{Kp}$ indices, whereas the PCC indices used with the non-linear function in equation (6) provide close fits to the Kp indices up to high levels.

\section{4 $\mathrm{PC}$ indices and the 1-min ring current indices}

Building the ring currents flowing near equator at distances of 4-6 Earth radii $\left(R_{\mathrm{E}}\right)$ is usually considered a feature related to the amount of energy supplied from the solar wind to the magnetosphere (Dessler \& Parker, 1959; Sckopke, 1966; Burton et al., 1975; Feldstein et al., 1984; Jorgensen et al., 2004). For the asymmetrical ring current index, ASY-H., Figures 9a and $9 \mathrm{~b}$ display a very close relation between average values of the polar cap PCC indices and the ASY-H indices all the way from near zero to high values of both indices representing magnetic storm cases. The close association could be related to the combined effects of a common electric field configuration and effects from injection of charged particles from the tail region to the inner magnetosphere during substorms associated with enhanced transpolar convection intensities that would generate large PC index values. The linear relation between the ASY-H and the PCC indices expressed in equation (7) is close to but not quite the same as the result (ASY-H = $13.1 \times$ PCC +11.5$)$ obtained by Stauning (2012) based on a different selection of magnetic storm events. The extended data base used here includes, in particular, many additional cases of valid PCS values, which are missing for most of 1996 and all of 2003 (cf. Fig. 4) that constitute a considerable fraction of the epoch (1995-2005) used formerly. Thus, the relation presented here $(\mathrm{ASY}-\mathrm{H}=10.9 \mathrm{PCC}+16)$ is considered to be the most accurate version. The relation between PCC and ASY-H in equation (7) was found at a delay of $8 \mathrm{~min}$ (PCC leading) to provide a correlation coefficient of $\mathrm{Rx}=0.743$.

Turning to other versions of the polar cap indices presented in Figures 10a-10d the most striking feature is the relations between the ASY-H index values and negative values of the $\mathrm{PCN}, \mathrm{PCS}, \mathrm{PC}_{\text {average}}$, and $\mathrm{PC}_{\text {winter }}$ indices. For positive $\mathrm{PC}$ index values the relations between average values are all close 
to being linear with slopes of around $10 \mathrm{nT} /(\mathrm{mV} / \mathrm{m})$, which is close to the slope of $10.9 \mathrm{nT} /(\mathrm{mV} / \mathrm{m})$ found for the relation between ASY-H and PCC. However, the relations with rising ASY-H values for increasing negative PC index values present a conceptual problem. The over-all correlation between ASY-H and the $\mathrm{PC}$ indices, around $\mathrm{Rx}=0.70$, is clearly lower than the correlation $(\mathrm{Rx}=0.74)$ between ASY-H and PCC.

The relations between the SYM-H index and the PCC indices are inconclusive apart from a general tendency of increased SYM-H values with increased PCC values (to be expected). Direct correlation between PC indices and SYM-H or Dst values beyond this trivial relation is not meaningful. This view is supported by the analysis of the relations between SYM-H and PC (here average of PCN and PCS) indices presented in Troshichev \& Sormakov (2018). Their Figure 1 displays the level of correlation between SYM-H and PC indices with varying degree of smoothing of both parameters. The correlation coefficient increases steadily from 0.590 at $15 \mathrm{~min}$ samples through 0.625 at hourly average samples to reach 0.657 (which may not be the maximum) at 120 min sample averaging. The low correlation at fast sampling indicates poor correspondence between simultaneous index values. The correlation coefficient values, e.g., $\mathrm{Rx}=0.625$ at hourly average samples, agree well with the estimates here of $\mathrm{Rx}=0.623$ for 15-min samples and $1 \mathrm{~h}$ shift.

\subsection{PC indices and the hourly ring current index, Dst}

Guided by the calculations presented by Burton et al. (1975) and using at first the decay time parameters devised by Feldstein et al. (1984) has enabled the calculations of equivalent Dst index values based on using PC indices in the source function. In the first step the gradients of archived Dst values were related to the PCC indices throughout 4-days segments of major magnetic storms (Dst(peak) $<-100 \mathrm{nT}$ ) during the epoch $1992-2018$ to provide a source function coefficient $Q \approx-4$ $[(\mathrm{nT} / \mathrm{h}) /(\mathrm{mV} / \mathrm{m})]$ (Eq. (10) and Fig. 12).

In the next step, the test bed comprising the 4-days segments of major magnetic storms was used to explore the dependencies of the equivalent Dst indicies on the control parameters such as the decay time parameters aiming at reaching the highest correlation values and least deviations with respect to the real Dst indices. For the tests, the equivalent Dst values were given initial values equal to the real Dst at the start of each 4-days storm interval and then built forward by integration of the combined source and decay functions.

The iteration of control parameters to reach an optimal result for the equivalent Dst index depends on the quality parameter considered, whether being the coefficients of correlation with the published (real) Dst values or the mean and rms differences, and also on the selection of samples considered. The Dst $t_{\mathrm{EQ}}$ for small and moderate events would match the real Dst values closer than seen in the strong events. Thus, from Table 4 it is clear that the quality parameters for the selection based on major storm events, as might be expected, is inferior to the selection based on all available samples. From the control parameter list in Table 3 it is seen that the decay times are longer for the storm event selection enabling the equivalent Dst values to reach higher values. In contrast, the decay times for the small and moderate events need to be shorter to allow the equivalent index values to decay back to zero. The more damped Dst $\mathrm{EQ}_{\mathrm{EQ}}$ course at the integration 1992-2018 needed a stronger boost from the high-level PCCeff samples to reach peak values in storm events comparable to those of the real Dst indices. Thus, there is no unique set of "correct" control parameters. The set of values presented in the "optimum all" column of Table 3 is considered the best compromise.

\subsection{The PC index as indicator of solar wind energy input}

In many reported investigations, the solar wind merging electric field, $E_{\mathrm{M}}$, (often named $E_{\mathrm{KL}}$ ) at the front of the magnetosphere is considered to control the amount of solar wind energy that enters the magnetosphere. Thus, the polar cap indices, since they are scaled with respect to $E_{\mathrm{M}}$, are considered to represent the input of solar wind energy to the magnetosphere to power various geomagnetic disturbances such as polar magnetic variations, auroral activities, substorms, upper atmosphere heating, and the building of ring currents (e.g., Troshichev et al., 1988, 2000, 2011b, 2014; Vennerstrøm et al, 1991; Troshichev \& Lukianova, 2002; Janzhura et al., 2007; Troshichev \& Sormakov, 2015, 2018, 2019). These investigations have been built on separate PCN or PCS indices or on their averages or on the summer/winter hemisphere PC index selections. Thus, the improved correlation with $E_{\mathrm{M}}$ resulting from using the PCC indices compared to using the other index versions might improve results from such investigations.

Considering the building of a ring current to represent energy input from the solar wind to the magnetosphere supports the concept of using the polar cap indices in a source function rather than comparing the $\mathrm{PC}$ indices directly to the actual ring current intensities. The development of the Dst ring current indices, in particular the negative peak values, relates to the intensity-time history of the PC indices and not to any specific instantaneous value.

\subsection{Quality control}

All aspects of the investigations of the relations between the polar cap indices and the merging electric field and the ring current properties rely critically on the quality of the basic magnetic data and their proper handling. Thus, all magnetic observational data involved here have been inspected in plots like the diagrams displayed in Figures $3 \mathrm{a}$ and $3 \mathrm{~b}$. From such plots and supported by yearly averages for international quiet (QQ) days, the component base lines have been controlled and - if needed - corrected to provide smooth secular variations only. The QDC values needed for defining the magnetic variations have also been displayed in yearly summary plots similar to the samples presented in Figure 9 of Stauning (2011) or in the reports (Stauning et al., 2006; Stauning, 2016). The PC indices have been inspected in monthly plots similar to the samples presented in Stauning et al. (2006) or Stauning (2016). And, finally, the derived equivalent Dst indices have been displayed along with the published Dst indices for each of the storm cases in plots like Figures $14 \mathrm{a}$ and $14 \mathrm{~b}$ and for the total interval 1992-2018 in diagrams like Figures 15a and 15b. Diagrams for the entire integration interval from 1992 to 2018 are included in the Appendix.

These control measures are considered necessary to avoid adverse cases like the PCS indices from 2011 supplied from 


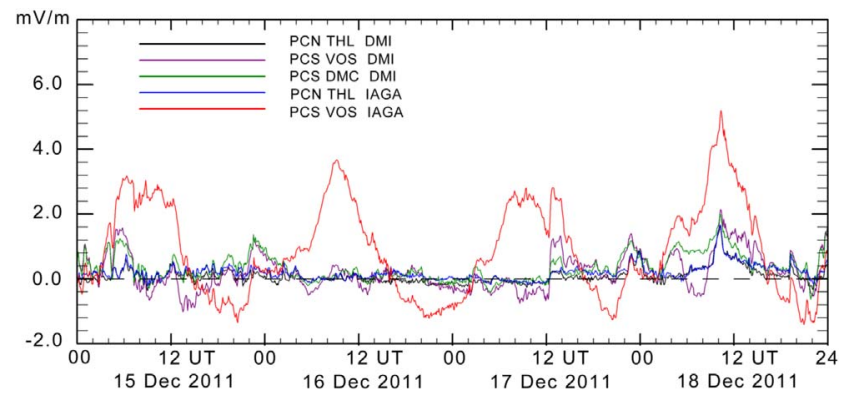

Fig. 16. Display of published PCN (blue line) and PCS (red) values from 15th to 18th December 2011. PCN values (black) from Qaanaaq data, PCS from Vostok (magenta) and Dome-C (green) data derived by a different method (DMI, Stauning, 2016) have been added to the diagram (Stauning, 2020).

the International Service of Geomagnetic Indices (ISGI) or from AARI (see Stauning, 2018a, 2020b) of which an example from December 2011 is displayed in Figure 16. The published Vostok-based PCS data derived at AARI display unjustified daily variations between -1.5 and up to $+4.0 \mathrm{mV} / \mathrm{m}$ (a level indicative of strong magnetic storm conditions). Figure 16 displays corresponding PCN and PCS values derived by the DMI index procedure (Stauning, 2016). The display of PCS index values based on Vostok data is supplemented by PCS index values derived from Dome-C (DMC) magnetic data, which are of adequate quality. The Vostok and Dome-C data generate nearly identical PCS values in the DMI versions and indicate very low disturbance levels at the times represented in Figure 16. The interval is very quiet (Kp values between 0 and 1 ) which is also evident from the PCN data in both versions.

The Vostok magnetic data used for the DMI calculations displayed in Figure 16 and supplied from INTERMAGNET are labelled "definitive" values and are of adequate quality. Hence, the erroneous PCS excursions must be caused by some failure in the AARI index calculations. Further examples of published erroneous PCS data are shown in the Supplementary Information file to Stauning (2020b)

The excessive PCS variations may have resided in the PCS index values calculated at AARI throughout the years and brought to attention now by the recent examination of PCS data. The PCS index failure underline the point that PC index series need careful monitoring and evaluation of index quality, which, apparently, has not been implemented for the PC index series published by AARI and ISGI. In addition, the magnetic data may have irregular variations as those displayed in Figures $3 \mathrm{~b}$ and should be handled with caution and care.

The combination of erroneous excessive PCS values (Fig. 16), questionable Vostok magnetic data (Fig. 3b), and lack of AARI documentation of index derivation methods make published results questionable.

\section{Summary}

\subsection{Correlation of PC indices with the merging electric field, $E_{M}$, and with $\mathrm{Kp}$ and $\mathrm{ASY}-\mathrm{H}$}

The examination of the relations between the solar wind merging electric field, $E_{\mathrm{M}}$, and the polar cap indices, $\mathrm{PCN}$,
PCS, and PCC presented in Figures 4-6 has demonstrated, unambiguously, that the non-negative combined PCC indices present higher values of the correlation with $E_{\mathrm{M}}$ than either of the PCN and PCS indices, their averages (PCA), or the seasonal selections, PCW for the winter, and PCU for the summer index values throughout all years of available data and throughout all seasons of the years. A summary of correlation coefficients is shown in Table 5. In addition to the PCC- $E_{\mathrm{M}}$ correlation with $\mathrm{Rx}=0.770$, the PCCD- $E_{\mathrm{M}}$ correlation (using Dome-C for questionable Vostok data 2012-2013) provides $\mathrm{Rx}=0.786$ (the best score of all).

The examinations have shown, in addition, that the correlations between $E_{\mathrm{M}}$ and PCN or PCS have considerable seasonal variations with minima at local summer conditions as displayed particularly clear in Figure 6. These minima are most likely related to the corresponding maxima in the intensities of reverse convection (DP3) events (cf. Fig. 2b). The seasonal variations have been mitigated in the PCC index version leaving a weak minimum at northern winter conditions (cf. Fig. 6).

\subsection{Relations between PC and Kp indices}

The PC indices respond to a considerable extent to the same disturbances as those reflected in the Kp indices. Although they may not be substituted for each other, the access to the 1-min $\mathrm{PC}$ indices in near real time may greatly enhance the timeliness of using $\mathrm{Kp}$ indices for space weather monitoring. Their better correlation as demonstrated in Tables 1 and 5 and avoiding confusing negative PC index values make the PCC indices the better choice over the individual PCN or PCS indices, their mean values, or the seasonal selections of PC index values for providing equivalent 3-hourly $\mathrm{Kp}$ values not tied to fixed UT hours. For the closest relations to the real $\mathrm{Kp}$ index values, the non-linear expression in equation (6) should be used with $\mathrm{PCC}$ index values to provide equivalent $\mathrm{Kp}$ values.

\subsection{Relations between PC indices and 1-min ring current indices}

The correlation between the 1-min asymmetrical ring current indices, ASY-H, and PC indices are much closer for the PCC index version than for other index versions as shown in Tables 2 and 5. The study of the relation between the $\mathrm{PCC}$ indices and the asymmetric ring current, ASY-H, indices has demonstrated a close linear relation with slope equal $10.9 \mathrm{nT} /(\mathrm{mV} / \mathrm{m})$. The displays in Figures $9 \mathrm{a}$ and $9 \mathrm{~b}$ present a moderate amount of scatter in the individual samples resulting in a correlation coefficient of 0.74 at a delay of $8 \mathrm{~min}$ (PCC leading). The corresponding relations between ASY-H and either of the PCN or PCS indices as well as their averages or the summer/winter hemisphere indices display about the same slope close to $10 \mathrm{nT} /(\mathrm{mV} / \mathrm{m})$ for positive index values but present irregular features at negative index values resulting in overall correlation coefficients of around 0.70 only.

The direct relation between the PCC indices and the 1-min SYM-H ring current indices present considerable scatter and poor correlation and should be considered inconclusive apart from a general tendency of related enhanced values presented by the two index series during disturbed conditions. 


\subsection{Relations between PC indices and the Dst hourly ring current index}

With fine-tuning of the control parameters and including corrections of the PCC indices for high-level saturation effects, the equivalent Dst indices were derived by integration of the source function (Eq. (8)) throughout the entire interval from 1992 to 2018 without any attachment to the real Dst index series. The correlation between the equivalent Dst index series using the source function based on the PCC indices derived from transpolar convection intensities and the real Dst indices based on near-equatorial magnetic observations reached a value of 0.856 at a delay of 45 min (PCC leading). The mean difference between the two series was below $1 \mathrm{nT}$, the mean absolute difference was below $10 \mathrm{nT}$, while the RMS difference was less than $13 \mathrm{nT}$.

The precise relations between the real and the PCCbased equivalent Dst has enabled fine-tuning of the timing parameters compared to the values provided by Feldstein et al. (1984) like shown in Table 3. The fast decay time has been reduced from $\tau=5.8$ to $5.5 \mathrm{~h}$, the slow from $\tau=8.2$ to $7.0 \mathrm{~h}$, and the cross-over level has been reduced from Dst $=-55$ to Dst $=-52 \mathrm{nT}$. Furthermore, a delay of $45 \mathrm{~min}$ between Dst $_{\mathrm{EQ}}$ (leading) and the real Dst was found for the optimal case.

At the extended integration, matching both the rare strong storm cases and the many small or moderate magnetic storms presented a problem. The problem was solved by introducing enhanced "effective" PCC values to compensate for the saturation effects at high disturbance levels. At PCC index levels above $5 \mathrm{mV} / \mathrm{m}$ an extra amount of 0.6.(PCC - 5) was added. This modification helped to make the equivalent Dst indices match the real Dst values well also during the strong storm events as seen in the displays in Figures $15 \mathrm{a}$ and $15 \mathrm{~b}$ and in the Appendix series of displays of Dst and Dst $t_{\mathrm{EQ}}$.

In a simplified version of the small contributions $(\approx 20 \mathrm{nT})$ from the magnetopause currents, the Dst (or SYM-H) indices could be derived by integration (summations in small steps) of the rate of change defined by equation (15) using the parameters from Table 3 and equations (13a) and (13b):

$$
\mathrm{d}\left(\mathrm{Dst}^{*}\right) / \mathrm{d} t=\operatorname{grad} D \times \mathrm{PCC}_{\text {eff }}-\mathrm{Dst}^{*} / \tau
$$

where

$$
\begin{aligned}
& \text { Dst }^{*}=\text { Dst }-20 \mathrm{nT} ; \\
& \operatorname{grad} D=-4.5(\mathrm{nT} / \mathrm{h}) /(\mathrm{mV} / \mathrm{m}) \\
& \mathrm{PCC}_{\text {eff }}=\mathrm{PCC} \text { if PCC }<5 \mathrm{mV} / \mathrm{m} \\
& \text { or } \mathrm{PCC}_{\text {eff }}=\mathrm{PCC}+0.6 \times(\mathrm{PCC}-5) \text { if PCC }>5 \mathrm{mV} / \mathrm{m} \text {; } \\
& \tau=5.5 \mathrm{~h} \text { if Dst }<-52 \mathrm{nT} \text { or } \tau=7.0 \mathrm{~h} \text { if Dst }>-52 \mathrm{nT} \text {. }
\end{aligned}
$$

Contrary to statements in Troshichev et al. (2011b), Troshichev \& Sormakov (2018), and ISO/TR/23989 (2020), the present work (cf. Fig 12) has no indication of thresholds in the PC indices for ring current increases or decays. The ring currents monitored through the Dst (or SYM-H) indices start increasing as the PCC index rises to a positive level, develops with the integrated time history of PCC according to equation (8) (or Eq. (15)), and decays when the PCC-based source function in equation (8) (or Eq. (15)) turns positive. There are no specific relations between the amplitude ratios or timing of PC maxima and Dst (or SYM-H) minima. The integration of equation (8) (or Eq. (15)) starting from quiet conditions (Dst $\approx 0$ ) provides fair Dst (or SYM-H) index values up to $\approx 45 \mathrm{~min}$ ahead of actual time. Real-time PCC-based Dst index source values provide the actual Dst (or SYM-H) forward slopes.

\section{Conclusions}

- The present work has provided a systematic assessment of the correlation between various PC index versions used in published works with the merging electric field, $E_{\mathrm{M}}$, in the solar wind and with ground-based global magnetic indices, the mid-latitude $\mathrm{Kp}$ index, and the ring current indices, ASY-H, SYM-H and Dst. The assessments provided here may support a qualified choice among available index versions.

- The relations between the polar cap PCC indices, built from non-negative values of the PCN and PCS indices, and the solar wind merging electric field, $E_{\mathrm{M}}$, are closer with markedly larger correlation coefficients than found for the relations between $E_{\mathrm{M}}$ and either of the PCN or PCS indices, their averages, or the summer or winter hemisphere PC index selections throughout all years and regardless of the season.

- For scaling or forecasting of global disturbance conditions using indices such as $\mathrm{Kp}$ or the asymmetric ring current index, ASY-H, related to substorm activity, their development should be monitored from the PCC indices rather than using either of the hemispherical PC indices or other possible PC index combinations to provide timely indications.

- The PC indices relate to the gradients (rate of change) in the ring current intensities monitored by the Dst or SYM-H indices. Accurate and detailed Dst or SYM-H values could be derived up to $45 \mathrm{~min}$ ahead of actual time by integration of the PCC-based source function from any previous quiet state. The direct correspondence between Dst or SYM-H levels (including peak values) and the instantaneous PC index values is poor.

- The close correspondence between real Dst and equivalent Dst index values derived with correlation $\mathrm{Rx}=0.86$ and standard deviation less than $13 \mathrm{nT}$ at the integration throughout 1992-2018 supports the concept of using the PCC index in a Dst source function.

- The accurate relations between the polar cap PCC indices in a source function and the Dst indices have enabled fine-tuning of timing parameters used in models of the ring current and has supported modification of the PCC index values to counteract their saturation at high disturbance levels.

- The high correlation and the accurate timing observed in the relations between the PCC indices based on transpolar convection of plasma and embedded magnetic fields and the ring current indices derived from near-equatorial magnetic variations may provide new insight in and improved modelling of the physical processes linking the polar and equatorial geomagnetic disturbance phenomena and help resolving their common origin in the solar wind properties. 
- The Polar Cap PC indices provide a great potential for space weather services by enabling monitoring of the input to the magnetosphere of solar wind energy used to power disturbance processes such as auroral activity, upper atmosphere heating, substorms, and geomagnetic storms. The PCC indices improve the accuracy over other PC index versions. Using multiple sources for PCN and PCS would improve service reliability.

\section{Data availability}

PCN and PCS index series derived by the IAGA-endorsed procedures are available through AARI and ISGI web sites. Archived PCN and PCS data used in the paper were downloaded from http://isgi.unistra.fr web portal in January 2020 unless otherwise noted. The web site, http://pcindex.org, holds PCN and PCS index coefficients and includes the descriptive document "Polar Cap (PC) Index" (Troshichev, 2011).

Geomagnetic data from Qaanaaq, Vostok, and Dome-C observatories were downloaded from the INTERMAGNET data service web portal at http://intermagnet.org. Ring current indices, Dst, SYM-H and ASY-H were downloaded from the web portal for World Data Centre WDC-C2 in Kyoto at http://swdcwww. kugi.kyoto-u.ac.jp/dstdir/index.html. Spacecraft data needed to generate the merging electric field values were downloaded from the OMNIweb service portal http://omniweb.gsfc.nasa.gov. Planetary Kp index values and SSC data were downloaded from the ISGI data service portal http://isgi.unistra.fr.

The magnetic observatory in Qaanaaq is managed by the Danish Meteorological Institute, while the magnetometer instruments are operated by DTU Space, Denmark. The Vostok observatory is operated by the Arctic and Antarctic Research Institute in St. Petersburg, Russia. The Dome-C observatory is managed by Ecole et Observatoire des Sciences de la Terre (France) and Istituto Nazionale di Geofisica e Vulcanologia (Italy).

The "DMI" PC index version is documented in the report SR-16-22 (Stauning, 2016) available at the website: http:// www.dmi.dk/fileadmin/user_upload/Rapporter/TR/2016/SR-1622-PCindex.pdf

Acknowledgements. The staffs at the observatories in Qaanaaq (Thule), Vostok, and Dome-C, and their supporting institutes are gratefully acknowledged for providing highquality geomagnetic data for this study. The efficient provision of space data from the IMP, ACE, Wind, and Geotail missions by the OMNIweb service, the supply of geomagnetic data from the INTERMAGNET data service centre, and the excellent performance of the ISGI and AARI PC index portals are greatly appreciated. The efforts from the many geomagnetic observatories involved in the collection of data for the Kp, Dst, SYM, and ASY indices and the processing at GFZ data centre in Potzdam and at WDCC2 in Kyoto is most gratefully acknowledged. The author gratefully acknowledges the collaboration and many rewarding discussions in the past with Drs. O. A. Troshichev and A. S. Janzhura at the Arctic and Antarctic Research Institute in St. Petersburg, Russia. The editor thanks Athanasios Boudouridis and two anonymous reviewers for their assistance in evaluating this paper.

\section{References}

Bartels J. 1957. The geomagnetic measures for the time variations of solar corpuscular radiation, described for use in correlation studies in other geophysical fields. Ann Intern Geophys Year 4: 227-236.

Burton RK, McPherron RL, Russell CT. 1975. An empirical relationship between interplanetary conditions and Dst. J Geophys Res 80: 4204-4214. https://doi.org/10.1029/JA080i031p04204.

Chambodut A, Di Mauro D, Schott JJ, Bordais P, Agnoletto L, Di Felice P. 2009. Three years continous record of the Earth's magnetic field at Concordia station (Dome-C, Antarctica). Annals of Geophysics 52: 15-24. https://doi.org/10.4401/ag-4569.

Davis TN, Sugiura M. 1966. Auroral electrojet activity index AE and its Universal Time variations. J Geophys Res 71: 785-801. https://doi.org/10.1029/JZ071i003p00785.

de Campra PF, de Artigas MZ. 2004. Comparison between indices during geomagnetic disturbances. Geofisica Internacional 43(1): 113-117.

Dessler AJ, Parker EN. 1959. Hydromagnetic theory of geomagnetic storms. J Geophys Res 64: 2239-2259. https://doi.org/10.1029/ JZ064i012p02239.

Di Mauro D, Cafarella L, Lepidi S, Pietrolungo M, Alfonsi L, Chambodut A. 2014. Geomagnetic polar observatories: the role of Concordia station at Dome C Antarctica. Ann Geophys 57(6): G0656https://doi.org/10.4401/ag-6605.

Dungey JW. 1961. Interplanetary magnetic field and the auroral zones. Phys Rev Lett 6: 47-48. https://doi.org/10.1103/ PhysRevLett.6.47.

Dungey JW. 1963. The structure of the exosphere or adventures in velocity space. In: Geophysics, the earth's environment. DeWitt C, Hieblot J, LeBeau L (Eds.), Gordon and Breach, New York, pp. 503-550.

Fairfield DH. 1968. Polar magnetic disturbances and the interplanetary magnetic field. COSPAR Space Research VII 107. https://doi. org/10.1029/JZ071i001p00155.

Feldstein YI, Pisarsky VYu, Rudneva NM, Grafe A. 1984. Ring current simulation in connection with interplanetary space conditions. Planet Space Sci 32: 975-984. https://doi.org/10.1016/00320633(84)90054-0.

Gao Y. 2012. On anomalous departures from a linear relation between the polar cap index and its controlling factors in the solar wind and magnetotail. J Geophys Res 117(A6): https://doi.org/ 10.1029/2012JA017721.

Gao Y, Kivelson MG, Walker RJ. 2012. The linear dependence of polar cap index on its controlling factors in the solar wind and magnetotail. J Geophys Res 117(A5): https://doi.org/10.1029/ 2011JA017229.

Huang C-S. 2005. Variations of polar cap index in response to solar wind changes and magnetospheric substorms. J Geophys Res 110: A01203. https://doi.org/10.1029/2004JA010616.

IAGA Resolution no. 3. 2013. http://www.iaga-aiga.org/resolutions.

Iyemori T, Araki T, Kamei T, Takeda M. 2000. Mid-latitude geomagnetic indices "ASY" and "SYM" for 1999. In: Geomagnetic indices home page. Iyemori $\mathrm{T}$ (Ed.), Kyoto University. WDC-C2 for Geomagnetism. http://swdcwww.kugi.kyoto-u.ac.jp/ dstdir/index.html.

Janzhura AS, Troshichev OA. 2011. Identification of the IMF sector structure in near-real time by ground magnetic data. Ann Geophys 29: 1491-1500. https://doi.org/10.5194/angeo-29-1491-2011.

Janzhura AS, Troshichev OA, Stauning P. 2007. Unified PC indices: Relation to the isolated magnetic substorms. J Geophys Res $\mathbf{1 1 2}$ A09207. https://doi.org/10.1029/2006JA012132. 
Jorgensen AM, Spence HE, Hughes WJ, Singer HJ. 2004. A statistical study of the ring current. J Geophys Res 109: A12204. https://doi.org/10.1029/2003JA010090.

Kan JR, Lee LC. 1979. Energy coupling function and solar windmagnetosphere dynamo. Geophys Res Lett 6(7): 577-580. https://doi.org/10.1029/GL006i007p00577.

Kappenman J. 2010. Geomagnetic storms and their impact on the U.S. power grid. Metatech Report, Meta-R-319, 197 p. Available at https://www.ferc.gov/sites/default/files/2020-05/ferc_meta-r-319.pdf.

Kuznetsov BM, Troshichev OA. 1977. On the nature of polar cap magnetic activity during undisturbed periods. Planet Space Sci $\mathbf{2 5}$ : 15-21. https://doi.org/10.1016/0032-0633(77)90113-1.

Matzka J. 2014. PC_index_description_main_document_incl_Appendix_ A.pdf. Available at DTU Space web portal: ftp://ftp.space.dtu.dk/ WDC/indices/pcn/.

Menvielle M, Iyemori T, Marchaudon A, Nosé M. 2011. Ch. 8: Geomagnetic indices. In: Geomagnetic observations and models. Mandea M, Korte M (Eds.), IAGA Special Sopron Book Series 5, pp. 183-228. https://doi.org/10.1007/978-90-481-9858-0_8.

Nielsen JB, Willer AN. 2019. Restructuring and harmonizing the code used to calculate the Definitive Polar Cap IndexReport from DTU Space. https://tinyurl.com/sx3g5t5.

Sckopke N. 1966. A general relation between the energy of trapped particles and the disturbance field near the Earth. J Geophys Res 71: 3125-3130. https://doi.org/10.1029/JZ071i013p03125.

Stauning P. 2007. A new index for the interplanetary merging electric field and geomagnetic activity: Application of the unified polar cap indices. Space Weather 5: S09001. https://doi.org/ 10.1029/2007SW000311.

Stauning P. 2011. Determination of the quiet daily geomagnetic variations for polar regions. J Atmos Solar Terr Phys 73: 2314-2330. https://doi.org/10.1016/j.jastp.2011.07.004.

Stauning P. 2012. The polar cap PC indices: relations to solar wind and global disturbances. In: Exploring the solar wind. Lazar M (Ed.), InTechOpen. ISBN: 978-953-51-0339-4. https://doi.org/ $10.5772 / 37359$.

Stauning P. 2013a. The Polar Cap index: A critical review of methods and a new approach. J Geophys Res Space Physics 118: 5021-5038. https://doi.org/10.1002/jgra.50462.

Stauning P. 2013b. Comments on quiet daily variation derivation in "Identification of the IMF sector structure in near-real time by ground magnetic data" by Janzhura and Troshichev (2011). Ann Geophys 31: 1221-1225. https://doi.org/10.5194/angeo-31-1221-2013.

Stauning P. 2013c. Power grid disturbances and polar cap index during geomagnetic storms. J Space Weather Space Clim 3: A22. https://doi.org/10.1051/swsc/2013044.

Stauning P. 2015. A critical note on the IAGA-endorsed Polar Cap index procedure: Effects of solar wind sector structure and reverse polar convection. Ann Geophys 33: 1443-1455. https://doi.org/ 10.5194/angeo-33-1443-2015.

Stauning P. 2016. The Polar Cap (PC) index: derivation procedures and quality control. DMI Scientific Report SR-16-22. Available at: https://www.dmi.dk/fileadmin/user_upload/Rapporter/TR/2016/ SR-16-22-PCindex.pdf.

Stauning P. 2018a. Multi-station basis for Polar Cap (PC) indices: ensuring credibility and operational reliability. J Space Weather Space Clim 8: A07. https://doi.org/10.1051/swsc/2017036.

Stauning P. 2018b. Reliable Polar Cap (PC) indices for space weather monitoring and forecast. J Space Weather Space Clim 8: A49. https://doi.org/10.1051/swsc/2018031.

Stauning P. 2020a. Using PC indices to predict violent GIC events threatening power grids. J Space Weather Space Clim. https://doi. org/10.1051/swsc/2020004.
Stauning P. 2020b. The Polar Cap (PC) index: invalid index series and a different approach. Space Weather 16: e2020SW002442. https://doi.org/10.1029/2020SW002442.

Stauning P, Troshichev OA, Janzhura A. 2006. Polar Cap (PC) index. Unified PC-N (North) index procedures and quality. DMI Scientific Report, SR-06-04. Available at https://www.dmi. dk/fileadmin/Rapporter/SR/sr06-04.pdf.

Stauning P, Troshichev OA, Janzhura AS. 2008. The Polar Cap (PC) index: Relations to solar wind parameters and global activity level. J Atmos Solar Terr Phys 70(18): 2246-2261. https://doi.org/ 10.1016/j.jastp.2008.09.028.

Stepanova M, Anatova E, Troshichev OA. 2005. Prediction of Dst variations from Polar Cap indices using time-delay neural network. J Atmos Solar Terr Phys 67: 1658-1664. https://doi.org/10.1016/ j.jastp.2005.02.027.

Sugiura M, Kamei T. 1981. Description of the hourly Dst index. In: Geomagnetic indices home page. Iyemori T (Ed.), Kyoto University, WDC-C2 for Geomagnetism. http://swdcwww.kugi.kyoto-u. ac.jp/dstdir/index.html.

Troshichev OA. 2011. Polar Cap (PC) Index. Available at: http:// pcindex.org (see Supported materials).

Troshichev OA. 2017. Polar cap magnetic activity (PC index) and space weather monitoring. Édition Universitaires Européennes, ISBN: 978-3-8381-8012-0.

Troshichev OA, Andrezen VG. 1985. The relationship between interplanetary quantities and magnetic activity in the southern polar cap. J Planet Space Sci 33: 415-419. https://doi.org/10.1016/ 0032-0633(85)90086-8.

Troshichev OA, Janzhura AS. 2012. Space Weather monitoring by ground-based means. Springer Praxis Books, Heidelberg. https://doi.org/10.1007/978-3-642-16803-1.

Troshichev AO, Lukianova RY. 2002. Relation of PC index to the solar wind parameters and substorm activity in time of magnetic storms. J Atmos Solar Terr Phys 64: 585. https://doi.org/10.1016/ S1364-6826(02)00016-0.

Troshichev OA, Sormakov DA. 2015. PC index as a proxy of the solar wind energy that entered into the magnetosphere: (2) Relation to the interplanetary electric field $E_{\mathrm{KL}}$. Earth Planets Space 67: 170. https://doi.org/10.1186/s40623-015-0338-4.

Troshichev OA, Sormakov DA. 2018. PC index as a proxy of the solar wind energy that entered into the magnetosphere: (3) Development of magnetic storms. J Atmos Solar Terr Phys 180: 60-77. https://doi.org/10.1016/j.jastp.2017.10.012.

Troshichev OA, Sormakov DA. 2019. PC index as a proxy of the solar wind energy that entered into the magnetosphere: (5) Verification of the solar wind parameters presented at OMNI website. J Atmos Solar Terr Phys 196: 105-147. https://doi.org/ 10.1016/j.jastp.2019.105147.

Troshichev OA, Andrezen VG, Vennerstrøm S, Friis-Christensen E. 1988. Magnetic activity in the polar cap - A new index. J Planet Space Sci 36(11): 1095-1102. https://doi.org/10.1016/0032-0633 (88)90063-3.

Troshichev OA, Dmitrieva NP, Kuznetsov BM. 1979. Polar Cap magnetic activity as a signature of substorm development. Planet Space Sci 27: 217. https://doi.org/10.1016/0032-0633(79)90063-1.

Troshichev OA, Janzhura AS, Stauning P. 2006. Unified PCN and PCS indices: method of calculation, physical sense and dependence on the IMF azimuthal and northward components. J Geophys Res 111: A05208. https://doi.org/10.1029/2005JA011402 (note correction in Troshichev et al., 2009).

Troshichev OA, Janzhura AS, Stauning P. 2009. Correction to "Unified PCN and PCS indices: Method of calculation, physical sense, and dependence on the IMF azimuthal and northward 
components". J Geophys Res 114: A11202. https://doi.org/ 10.1029/2009JA014937.

Troshichev AO, Lukianova RY, Papitashvili VO, Rich FJ, Rasmussen O. 2000. Polar Cap index (PC) as a proxy for ionospheric electric field in the near-pole region. Geophys Res Lett 27: 3809. https://doi.org/10.1029/2000GL003756.

Troshichev OA, Podorozhkina NA, Janzhura AS. 2011a. Invariability of relationship between the polar cap magnetic activity and geoeffective interplanetary electric field. Ann Geophys 29(14791489): 2011. https://doi.org/10.5194/angeo-29-1479-2011.

Troshichev OA, Podorozhkina NA, Sormakov DA, Janzhura AS. 2014. PC index as a proxy of the solar wind energy that entered into the magnetosphere: 1. Development of magnetic substorms. J Geophys Res (Space Phys) 119: 6521. https://doi.org/10.1002/ 2014JA019940.

Troshichev OA, Sormakov DA, Janzhura AS. 2012. Relations between PC index and substorm (AL) and storm (SYM, ASYM) indices under conditions of the steady high solar wind energy input into the magnetosphere. Adv Space Res 49: 872-882. https://doi. org/10.1016/j.asr.2011.12.011.
Troshichev OA, Sormakov DA, Janzhura AS. 2011b. Relation of PC index to the geomagnetic storm Dst variation. J Atmos Solar Terr Phys 73: 611-622. https://doi.org/10.1016/j.jastp.2010.12.015.

Vennerstrøm S. 1991. The geomagnetic activity index PC. PhD Thesis, DMI Scientific Report 91-3. Danish Meteorological Institute, 105 p. https://www.dmi.dk/fileadmin/user_upload/Rapporter/SR/1991/sr91-3.pdf.

Vennerstrøm S, Friis-Christensen E, Troshichev OA, Andrezen VG. 1991. Comparison between the polar cap index PC and the auroral electrojet indices AE, AL and AU. J Geophys Res Space Phys 96 (A1): 101-113. https://doi.org/10.1029/90JA01975.

Reference is made to the ISO report. 2020. Space environment (natural and artificial) - Operational estimation of the solar wind energy input into the Earth's magnetosphere by means of the ground-based Polar Cap (PC) index. International Organization for Standardization, ISO Technical Report ISO/TR/23989-2020. https://www.iso.org/standard/77565.html. 


\section{Appendix}

\section{Integration 1992-2018}

Start: Dst $_{\mathrm{EQ}}=0$ on 1 January 1992. No attachment to Dst.
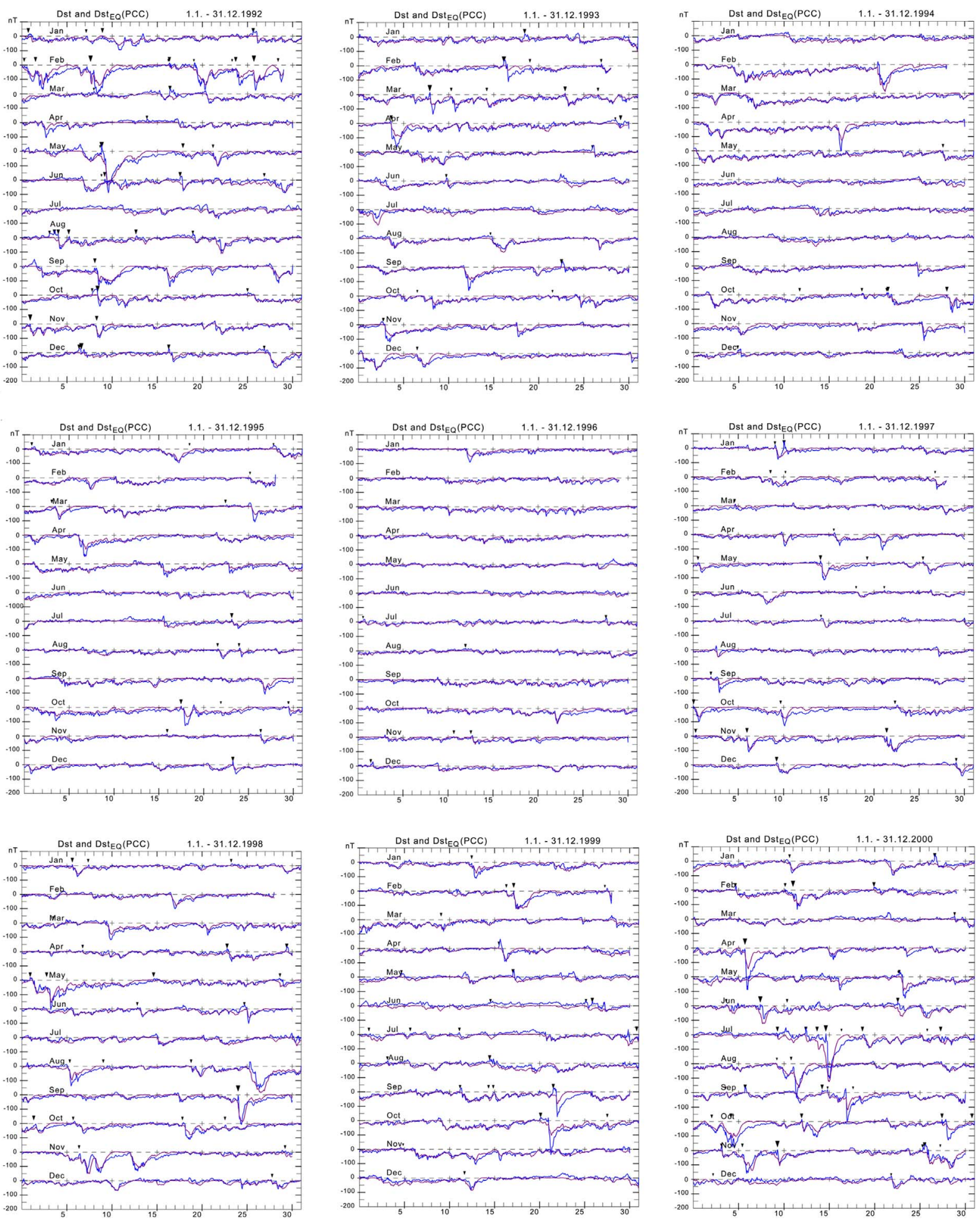

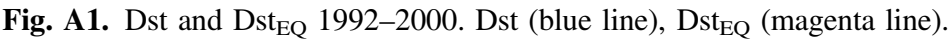



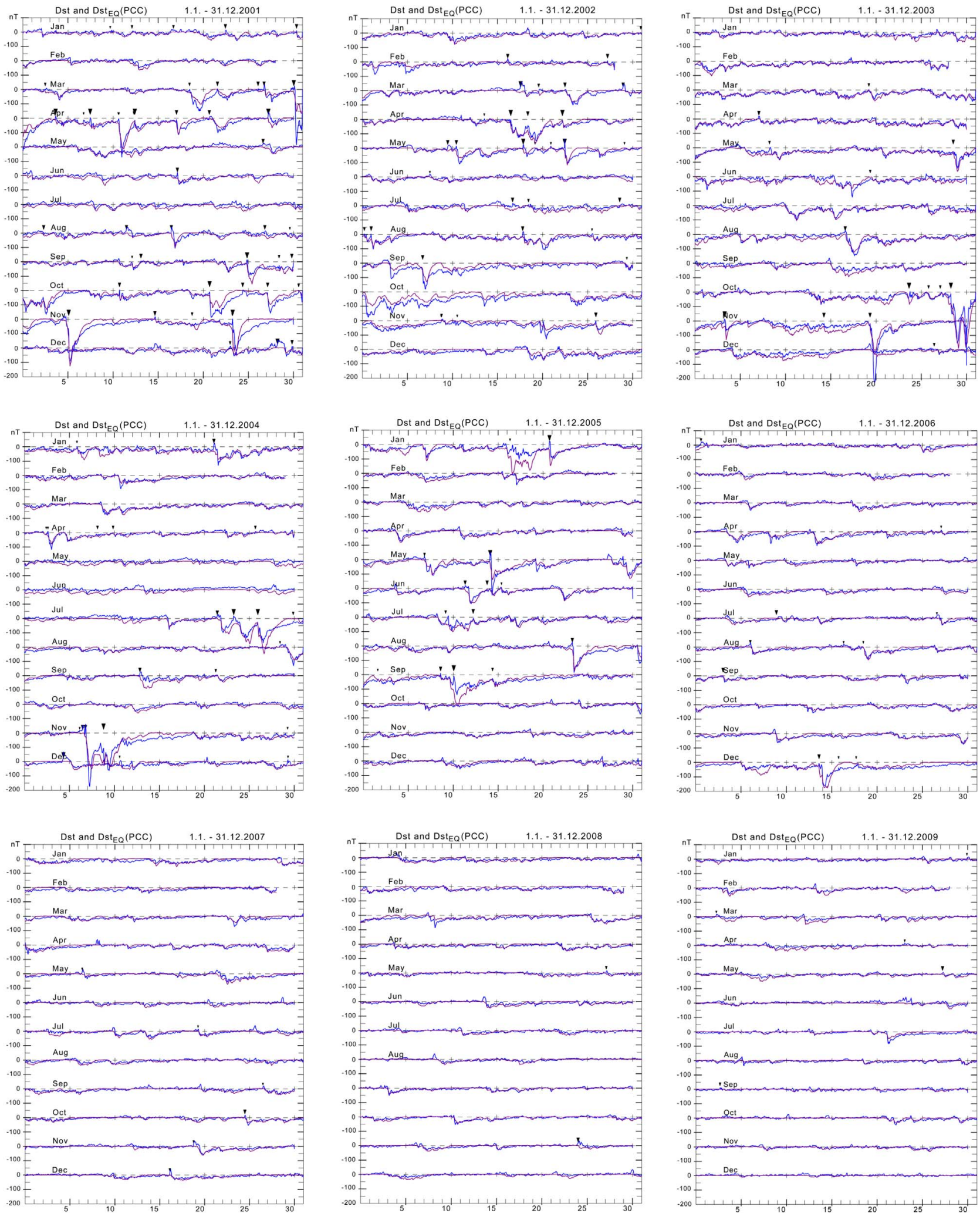

Fig. A2. Dst and Dst ${ }_{\mathrm{EQ}}$ 2001-2009. 

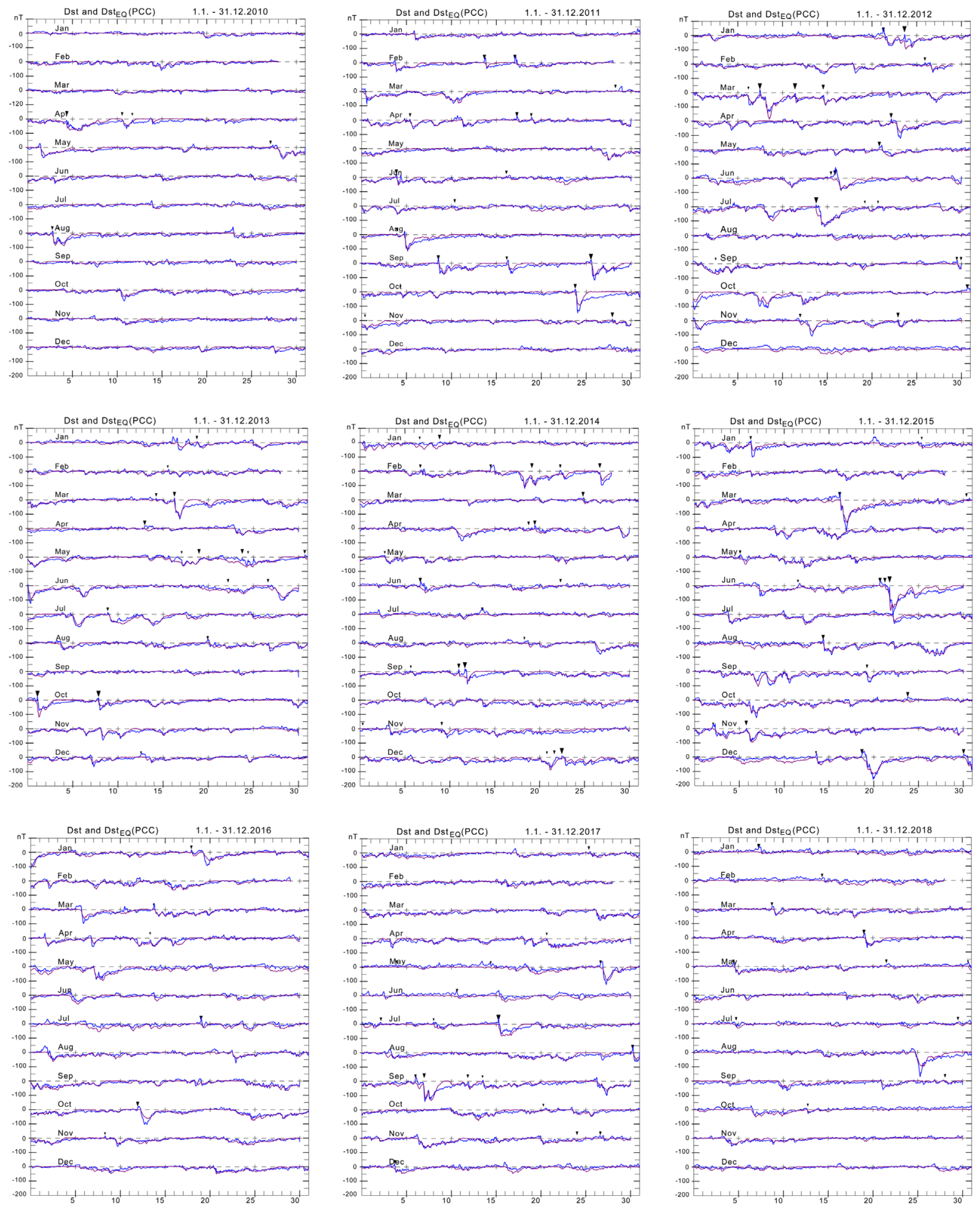

Fig. A3. Dst and Dst $\mathrm{EQ}_{2} 2010-2018$.

Cite this article as: Stauning P 2021. The Polar Cap (PC) index combination, PCC: relations to solar wind properties and global magnetic disturbances. J. Space Weather Space Clim. 11, 19. https://doi.org/10.1051/swsc/2020074. 